\title{
Lung Injury and Lung Cancer Caused by Cigarette Smoke-Induced Oxidative Stress: Molecular Mechanisms and Therapeutic Opportunities Involving the Ceramide-Generating Machinery and Epidermal Growth Factor Receptor
}

Tzipora Goldkorn, Simone Filosto, and Samuel Chung

\begin{abstract}
Chronic obstructive pulmonary disease (COPD) and lung cancer are frequently caused by tobacco smoking. However, these diseases present opposite phenotypes involving redox signaling at the cellular level. While COPD is characterized by excessive airway epithelial cell death and lung injury, lung cancer is caused by uncontrolled epithelial cell proliferation. Notably, epidemiological studies have demonstrated that lung cancer incidence is significantly higher in patients who have preexisting emphysema/lung injury. However, the molecular link and common cell signaling events underlying lung injury diseases and lung cancer are poorly understood. This review focuses on studies of molecular mechanism(s) underlying smoking-related lung injury (COPD) and lung cancer. Specifically, the role of the ceramide-generating machinery during cigarette smoke-induced oxidative stress leading to both apoptosis and proliferation of lung epithelial cells is emphasized. Over recent years, it has been established that ceramide is a sphingolipid playing a major role in lung epithelia structure/function leading to lung injury in chronic pulmonary diseases. However, new and unexpected findings draw attention to its potential role in lung development, cell proliferation, and tumorigenesis. To address this dichotomy in detail, evidence is presented regarding several protein targets, including Src, p38 mitogen-activated protein kinase, and neutral sphingomyelinase 2, the major sphingomyelinase that controls ceramide generation during oxidative stress. Furthermore, their roles are presented not only in apoptosis and lung injury but also in enhancing cell proliferation, lung cancer development, and resistance to epidermal growth factor receptor-targeted therapy for treating lung cancer. Antioxid. Redox Signal. 21, 2149-2174.

I. Introduction

II. Oxidative Stress and Pulmonary Disease 2151

A. Smoking, oxidative stress, and inflammation 2151

B. Smoking and emphysema/lung injury: the role of apoptosis in the disease development 2152

III. The Role of Ceramide in Oxidative Stress-Induced Lung Epithelial Apoptosis

A. Neutral sphingomyelinase 2-induced ceramide generation as a specific target in CS-induced lung injury

B. The surprising role of Src in controlling nSMase2/ceramide generation 2153

IV. Oxidative Stress and Lung Cancer

A. Stress-driven endocytosis of tyrosine-phosphorylated EGFR leads to tumorigenesis: the critical role of oxidative stress

1. Canonical EGFR activation, intracellular trafficking, and degradation

2. CS produces $\mathrm{H}_{2} \mathrm{O}_{2}$-induced oxidative stress that aberrantly activates EGFR

Reviewing Editors: Mara Benfato, Marcel Bonay, Maria M. Facchinetti, Marie Hanigan, Petr Heneberg, Weihong Hou, and Yuichiro Suzuki

Center for Comparative Respiratory Biology and Medicine, Genome and Biomedical Sciences Facility, University of California School of Medicine, Davis, California. 
3. The lack of c-Cbl binding to EGFR causes prolonged proliferation signaling under oxidative stress

4. EGFR perinuclear sorting under oxidative stress

5. An aberrant activated conformation of EGFR under oxidative stress underlies lung cancer resistance to targeted therapy

V. Smoking and Lung Diseases: The Enigmatic Association Between Lung Injury and Lung Cancer

VI. The Dichotomous Response of Airway Epithelial Cells to CS Oxidants: A Critical Role for Src

VII. The Unexpected Role of Ceramide in Cell Proliferation and Tumorigenesis

A. Cell membrane ceramide-enriched signaling platform and stabilization of aberrantly activated EGFR

B. Membrane ordered lipid domains

C. Ceramide selectively displaces cholesterol from ordered lipid domains (rafts)

D. Ceramide/cholesterol ratio affects EGFR and Src

E. Ceramide, EGFR, and Src

F. The link between ceramide and Src underlies their dual roles in apoptosis and proliferation

VIII. Propagation of Oncogenes and miRNA via nSMase2-Dependent Ceramide Generation and Exosome Secretion

\section{Introduction}

C IGARETTE SMOKE (CS) causes chronic diseases, particularly lung diseases, which are the major source of morbidity and mortality that accounts for over 400,000 deaths per year in the United States alone (14). Therefore, the causes of smoking-associated diseases, as well as potential therapeutic treatments for those diseases, are topics of great international interest and high importance for human well-being (95). Research studies in health-related tobacco smoke exposures initially developed in the early 1970s. Despite nearly 40 years of research involving a worldwide scientific community (13, 95), we are still far away from a sound understanding of the molecular mechanisms underlying smoking-induced chronic lung diseases, due to the diverse pathological respiratory conditions attributed to smoking $(6,79)$. Most notably, chronic obstructive pulmonary disease (COPD) and lung cancer are frequently triggered by smoking ( $80 \%-90 \%$ of all cases) because of its widespread use.

Despite sharing a common etiology of tobacco smoke exposure, COPD (which includes chronic bronchitis in the main airways and emphysema in the parenchymal tissue) and lung cancer differ at the cellular level. Epithelial cell death, which results in tissue destruction and injury, is one of the main features of COPD, whereas lung cancer is characterized by uncontrolled clonal growth of the lung epithelial cells. Furthermore, many epidemiological studies over the years have established increased lung cancer risk and incidence in COPD patients (79). Intriguingly, smoking cessation does not significantly reduce the risk of developing lung cancer, which may be explained by persistent lung oxidative stress and inflammation even after smoking cessation (7). For example, a large prospective trial of nonsmokers demonstrated that lung cancer incidence is common in patients with nonsmoking COPD (211), emphasizing that oxidative stress and chronic inflammation, which are the characteristics of all patients with COPD, could be common determinants in the association between COPD and lung cancer. In addition, mild-tomoderate disease stages of COPD patients (GOLD 1 and 2 standards, respectively) present even higher risk for developing lung cancer than severe (GOLD 4) ones (44). While longer survival of early-stage COPD patients can explain this phenomenon, it is unlikely to be the only reason. That withstand, this association between COPD and lung cancer is not surprising because cancer has been long considered a chronic "wound that does not heal," which occurs in conditions such as chronic oxidative stress and inflammation mirrored in all patients with COPD (52). Therefore, injuryinitiated repair mechanisms could represent an opportunity for cancer to develop. However, the molecular mechanism(s) and cell signaling pathways underlying these clinical observations are still poorly understood (Fig. 1).

An increasing number of studies demonstrate that increased oxidant burden in smokers contributes to lung injury through many biological actions, including epithelial injury via apoptosis (79). Moreover, markers of oxidative stress (pathological accumulation of reactive oxygen species [ROS]), such as hydrogen peroxide $\left(\mathrm{H}_{2} \mathrm{O}_{2}\right)$, are elevated in the breath and serum of COPD patients (200) and documented to be present in all stages of COPD (62). At the same time, exactly how oxidative stress incites COPD association with lung cancer is poorly understood at the molecular level, despite a role for oxidative stress having widely been proposed in cancer initiation and promotion $(65,89,143)$. Such molecular underpinning could possibly be found at both genetic and epigenetic levels, and therefore, further studies are needed in these directions (3). For example, Malhotra et al. found that a reduction in the activity of the transcription factor nuclear factor (erythroid-derived 2)-like 2 (Nrf2) reduces the expression of antioxidants, such as heme oxygenase-1 


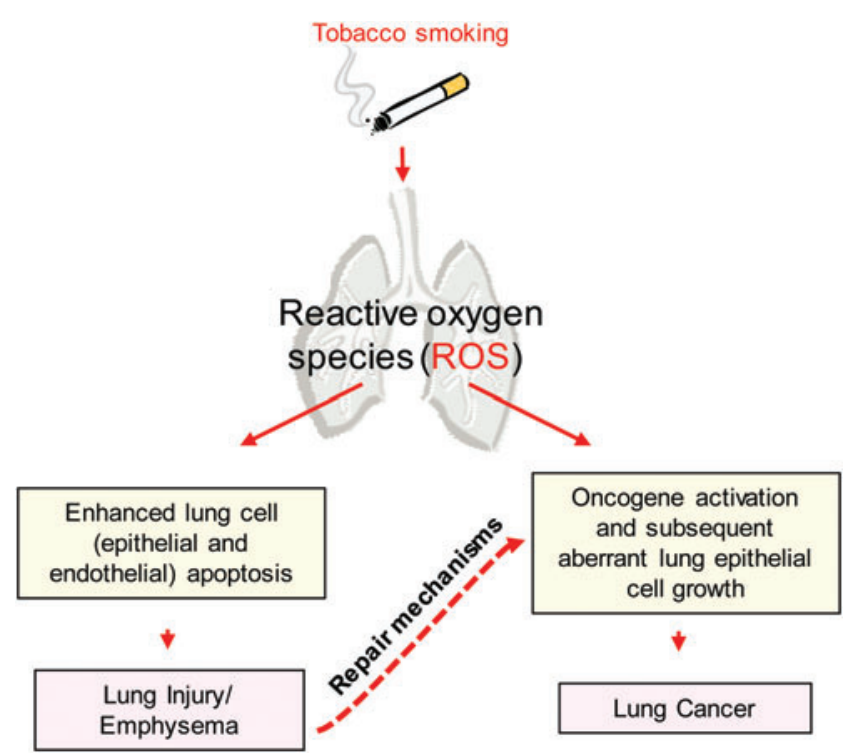

FIG. 1. Tobacco smoke-generated ROS, which cause both aberrant cell death and proliferation of lung epithelial cells, lead to the development of emphysema and lung cancer, respectively. The oxidative stress-dependent increase in apoptosis of lung resident (epithelial and endothelial) cells represents a major initiating event for emphysema development (lung parenchymal injury) in smokers. At the same time, the oxidative stress-dependent oncogene activation and cell hyperplasia lead to lung cancer development. Therefore, preexisting emphysema increases the risk for lung cancer development. ROS, reactive oxygen species. To see this illustration in color, the reader is referred to the web version of this article at www.liebertpub.com/ars

(HO1) and glutamate-cysteine ligase in COPD patients, thus increasing oxidative stress markers (140). Similar findings were demonstrated in vitro by Goven et al. (82) and ex vivo (83) in lung biopsies from emphysema patients. The downregulation of Nrf2-dependent genes that are involved in the detoxification of CS constituents could lead to enhanced carcinogenic potential and also increase the metastasis of lung cancers (24).

Notably, most molecular studies in airway epithelial cells center on the mechanism(s) of either cell death or proliferation $(76,118,119,176,177)$. However, cell death and hyperplasia of airway epithelial cells as well as infiltration of inflammatory cells occur simultaneously during lung injury and repair, as documented by animal- and cell-level studies $(45,53,96,115,147,164,179,200,235)$. Thus, the mechanisms of cell death and proliferation in the lung constitute two sides of the same coin (Fig. 1). Since these two events are intimately related with each other (50), the scope of this review is not only to present evidence underlying cell death (lung injury) and cell proliferation (lung cancer) during CSinduced oxidative stress but also to discuss a possible molecular interplay between the two pathological conditions. Studies by Goldkorn et al. demonstrated that the oxidative stress component of CS, an equivalence of $200-600 \mu M \mathrm{H}_{2} \mathrm{O}_{2}$ generated in situ per cigarette, is the driving force behind both smoke-induced cell death (via ceramide generation) and smoke-induced proliferation (via epidermal growth factor receptor [EGFR] activation) (77, 80, 118, 119, 133, 134).
These studies are discussed herein together with novel concepts regarding the dichotomous roles of Src in regulating both the ceramide-generating machinery and aberrant EGFR signaling in the pathology of airway epithelial cells exposed to CS-induced accumulation of ROS (CS/oxidative stress). The goal is to provide breath in a challenging and mostly undefined research field that will lead to a better understanding of the molecular connections between smokingrelated lung injury and lung cancer.

\section{Oxidative Stress and Pulmonary Disease}

Oxidative stress reflects an imbalance between the systemic manifestation of ROS and a biological system's ability to readily detoxify the reactive intermediates and to repair the resulting damage. ROS are a group of ubiquitous molecules that include species, such as superoxide anion $\left(\mathrm{O}_{2}{ }^{-}\right), \mathrm{H}_{2} \mathrm{O}_{2}$, and hydroxyl radicals $(\bullet \mathrm{OH})$. Given that ROS are involved in multiple biologic processes and signal cascades that include normal tissue homeostasis $(101,192)$, changes to local and global ROS levels directly contribute to the development of many human diseases. In particular, this review focuses on lung diseases since the respiratory system is constantly exposed to gaseous oxygen and ROS, which are quelled by nonenzymatic and enzymatic antioxidant defenses, including glutathione (GSH), superoxide dismutase, and catalase (91). However, when the lung is chronically exposed to oxidants such as ozone $\left(\mathrm{O}_{3}\right)(154)$ or to those in tobacco smoke, these mechanisms become overwhelmed, leading to the development of pulmonary diseases $(144,235)$.

Initially, the involvement of ROS in disease was explained with simplistic chemistry in which critical cell proteins and lipids were randomly oxidized and became inactive for their roles in normal cell function (90). Accordingly, antioxidants such as GSH or $\alpha$-tocopherol were viewed simply as free radical scavengers. More recently, however, ROS have been recognized to function as signaling molecules. Several studies demonstrate the various roles for ROS in the pathogenesis of pulmonary diseases, such as acute respiratory distress syndrome, COPD, asthma, interstitial pulmonary fibrosis $(9,90$, 101, 173-175), and lung cancer $(58,61,119)$. Among these diseases, both COPD and lung cancer share a common etiology rooted in exposure to tobacco smoke ( $80 \%-90 \%$ of the cases), a major source of oxidative stress (as described in Sections III and IV) (Fig. 1).

\section{A. Smoking, oxidative stress, and inflammation}

Despite the well-documented dangers of smoking, millions of people continue to smoke cigarettes daily, each puff containing roughly 5000 toxic compounds in addition to over $10^{15}$ free radicals, such as $\mathrm{H}_{2} \mathrm{O}_{2}$ and hydroxyl and organic radicals in the gaseous phase (30). Importantly, toxic oxidants in tobacco smoke have a detrimental effect on epithelial cells lining the airway, causing both oxidative stress and inflammation, which contribute to several lung pathological conditions, including $\operatorname{COPD}(79,184)$.

COPD is a lung disease endemic among smokers, with little to no therapeutic options. Such lung injury diseases adversely affect more than 16 million people in the United States, with another 50 million estimated to be at risk (2, 155). Up to $85 \%$ of COPD cases are directly attributed to smoking and smokers are 10 times more likely to develop 
COPD than nonsmokers. Importantly, these diseases have no treatments that effectively restore function because they involve destructive and lasting enlargement of distal airspaces and alveolar walls $(1,54,169)$, which eventually leads to impaired oxygenation of the blood.

The pathogenesis of emphysema has historically been attributed to protease-antiprotease imbalance resulting from chronic lung inflammation (210). Initially, genetic deficiency in $\alpha-1$ antitrypsin, a major elastase inhibitor released by neutrophils, was attributed to hastened development of emphysema and led to the hypothesis that levels and activity of proteases and antiproteases play a critical role in emphysema pathogenesis (139). Since then, several studies have shown that chronic exposure to inhaled irritants (the most common being tobacco smoke) leads to chronic inflammation in the lung, during which recruited inflammatory cells release various proteases that destroy the extracellular matrix and lead to the loss of alveolar units (152). Specifically, exposure to tobacco smoke has been shown to increase gene expression and release of cytokines, such as interleukin-8 and tumor necrosis factor- $\alpha(\mathrm{TNF}-\alpha)$, in both human airway epithelial (HAE) cells and murine models $(31,32,148)$. Subsequent recruitment of neutrophils to the lung leads to localized inflammation, during which apoptosis of irreparable cells and proliferation/differentiation of progenitor cells drive tissue repair (97). At the same time, recruited neutrophils and resident alveolar macrophages secrete matrix metalloproteases (MMPs), such as MMP-2 and MMP-9, and serine proteases, which act to breakdown the extracellular matrix to generate niches for newly dividing cells (207). Importantly, these normal processes become usurped during chronic exposure to tobacco smoke, contributing to pathological alveolar and overall lung destruction. However, the concept of inflammation as the initiator of the cascade of events in lung destruction in diseases such as COPD has recently been challenged. Instead, inflammation could represent the result of a long-standing destructive process in the lung and by itself might be a source of additional injury.

\section{B. Smoking and emphysema/lung injury: the role of apoptosis in the disease development}

Recent studies provide a very strong case for cell death having a major role in lung injury in several smoking-related pulmonary diseases. In simple terms, the loss of cells by augmented apoptosis would be expected to be involved, or perhaps, initiate the overall tissue destruction responsible for smoking-induced lung injury $(45,54,96,115,117,164,191$, 200, 235). This "cell death" hypothesis arose in part due to the observations that smokers with emphysema have increased levels of apoptotic alveolar cells compared to smokers without emphysema (116). Subsequent studies demonstrated that experimental induction of either vascular endothelial cell apoptosis or pulmonary epithelial cell apoptosis in animal models resulted in airspace enlargement $(45,75,169)$. For instance, when mice were given a single intracellular injection of active caspase-3 (executioner of apoptosis), the treatment resulted in alveolar epithelial apoptosis followed by alveolar wall damage and airspace enlargement $(8,209)$. Loss of cells by elevated apoptosis is thus a crucial initiator of the overall tissue damage in COPD (Fig. 1), which could explain the unique nature of alveolar septal damage in emphysema when compared with other lung diseases that are also characterized by inflammation and elevated matrix proteolysis. The irreversible pattern of the disease even when the patient stops smoking (209) could well be accredited to the frequent interface between apoptosis, inflammation, oxidative stress, and matrix proteolysis.

Given the critical role of apoptosis in the pathogenesis of emphysema/lung injury, ceramide, a sphingolipid molecule that serves as a second messenger that modulates cell apoptosis $(22,77,80,92,130,178)$, oxidative stress $(130)$, and proteolysis (180), was proposed to be deregulated during the pathogenesis of lung injury diseases, such as COPD, causing induction of alveolar destruction via apoptosis of epithelial and endothelial cells $(45,59)$. Therefore, the elucidation of the molecular mechanism(s) that modulate the ceramidegenerating machinery in the lungs is essential and could lead to the development of improved mechanism-specific drugs for the treatment or prevention of pulmonary injury diseases.

\section{The Role of Ceramide in Oxidative Stress-Induced Lung Epithelial Apoptosis}

As mentioned before, epithelial cells line both the lung main airways and the terminal alveoli and thus represent the lung's first line of defense-they are extensively exposed to reactive oxidants, such as those present in CS. As introduced earlier, cell signaling events that are initiated in HAE cells during CS exposure lead to either apoptosis (hallmark of injury) or proliferation (hallmark of cancer), as extensively explored both in vitro and in vivo $(59,119,134)$. Notably, different stimuli in vitro acting at diverse sites to activate ceramide accumulation trigger apoptosis (178). Specifically, exogenous $\mathrm{C}_{6}$-ceramide was sufficient to induce apoptosis in human lung epithelial cells, supporting the concept that elevated ceramide levels, per se, is sufficient to initiate the apoptotic cascade in lung epithelial cells and that ceramide accumulation is a causative signal for apoptosis induction (178) and not just an outcome of epithelial cell death.

The initial studies addressing oxidative stress-induced lung injury investigated whether HAE cells undergo apoptosis when exposed to $\mathrm{H}_{2} \mathrm{O}_{2}$, concentrations of about 50-250 $\mu M$, and consequently whether this process is mediated by ceramide generation $(22,77)$. It was shown that either the administration of exogenous $\mathrm{H}_{2} \mathrm{O}_{2}$ or the enhancement of endogenously generated $\mathrm{H}_{2} \mathrm{O}_{2}$ was effective in depleting cellular GSH and initiating ceramide generation and apoptosis events (178). Both a dose-dependent relationship (50-250 $\mu \mathrm{M}$ $\mathrm{H}_{2} \mathrm{O}_{2}$ ) and a time-dependent relationship were observed between $\mathrm{H}_{2} \mathrm{O}_{2}$ exposure and increased cellular ceramide levels and subsequent apoptosis. Interestingly, even a short 1-h exposure of cells to $250 \mu M \mathrm{H}_{2} \mathrm{O}_{2}$, followed by growth in regular medium, was sufficient to induce apoptosis (130).

As a ubiquitous antioxidant, GSH, a tripeptide ( $\mathrm{L}-\gamma-$ glutamyl-L-cysteinyl-glycine) containing a sulfhydryl group that enables it to be a key intracellular reducing agent, is an essential component of the antioxidant defense mechanism in oxidant-induced lung injury. Notably, both lung epithelial cells and the epithelial lining fluid contain high concentrations of GSH (130). Importantly, Lavrentiadou et al. demonstrated that low GSH levels were essential for ceramide generation, whereas high GSH levels inhibited the production of ceramide in HAE cells (in vitro), which showed that GSH plays a critical role in preventing lung epithelial cell death (130). This 
demonstrated that the events that control the fate of the cells occur within this hour, during the time shown that GSH is depleted and ceramide is generated (130). This initial model for $\mathrm{H}_{2} \mathrm{O}_{2}$-induced cellular oxidative stress and ceramide generation consisted of direct exposures of airway epithelial cells to $\mathrm{H}_{2} \mathrm{O}_{2}$ and GSH or N-acetyl cysteine (NAC), a cell-permeable precursor of GSH. Moreover, an increase of intracellular $\mathrm{H}_{2} \mathrm{O}_{2}$, mediated by inhibition of catalase by aminotriazole, also induced ceramide generation and apoptosis $(118,130,178)$. Although these early studies undertook a reductionist, simplified approach, both scenarios were relevant to the lung epithelium. $\mathrm{H}_{2} \mathrm{O}_{2}$ is a ubiquitous molecule that is freely miscible and able to cross cell membranes readily and is present in several air pollutants, including the tobacco smoke (119). It is detected in exhaled air of humans (222), and the amounts of exhaled $\mathrm{H}_{2} \mathrm{O}_{2}$ appear greater in subjects with pulmonary disease (205) and in smokers.

Later, in vitro studies showed that CS exposure regulates both growth and death of airway epithelial cells via its $\mathrm{H}_{2} \mathrm{O}_{2}$ component $(119,130)$ : CS exposure could generate between 100 and $800 \mu M \mathrm{H}_{2} \mathrm{O}_{2}$ in situ, as measured in the media of cultured HAE cells, a factor that was dependent on the length of exposure and the amount of combusted tobacco. Furthermore, when the CS-generated $\mathrm{H}_{2} \mathrm{O}_{2}$ was quenched by antioxidants, such as GSH or NAC, no enhanced ceramide generation was observed (119). Since then, it has been shown that exposure to oxidative stress generated by either CS exposure or direct administration of $\mathrm{H}_{2} \mathrm{O}_{2}$ leads to an increase of ceramide level before caspase-3dependent apoptosis in airway epithelial cells, mimicking the dominant apoptotic process of emphysema pathogenesis (178). Following this discovery, the potential enzymatic regulators controlling this phenomenon were investigated.

\section{A. Neutral sphingomyelinase 2-induced ceramide generation as a specific target in CS-induced lung injury}

Ceramide generation through sphingomyelin hydrolysis is known to have a key role in various types of cell stress induction. While several sphingomyelinases (SMases) may be able to accomplish such ahydrolysis, only some SMases may have unique pathological importance $(20,21,34,59,60,77,79$, $158,178,182,212,224)$. Initial in vitro studies showed that an SMase(s) operating at neutral $\mathrm{pH}$ was responsible for ceramide generation in HAE cells exposed to oxidative stress (133). Therefore, a considerable effort of purification and cloning of a putative protein from the lungs of nonhuman primates and HAE cells led to the independent isolation and characterization of a novel SMase, neutral sphingomyelinase 2 (nSMase2; SMPD3 gene), as the only accountable source for ceramide generation as a result of oxidative stress induction (133).

Subsequently, it was shown that nSMase 2 was activated in $\mathrm{HAE}$ cells (in vitro) not only by $\mathrm{H}_{2} \mathrm{O}_{2}$-generated oxidative stress but also in response to $\mathrm{CS}$ exposure and subsequent oxidative stress $(133,134)$. Moreover, silencing of nSMase 2 expression using siRNA fully abolished ceramide production and the downstream apoptotic outcomes in response to oxidative stress. At the same time, mice heterozygous for nSMase2 (+/-) demonstrated significantly reduced lung ceramide generation when exposed to CS. Intriguingly, nSMase2 also is overexpressed in human emphysema patients (smokers) and rodents chronically exposed to CS. These studies clearly implicated nSMase 2 activation and the subsequent ceramide generation in lung airway epithelial injury during CS-induced oxidative stress (59) (Fig. 2).

The molecular mechanism that controls nSMase 2 function in response to oxidative stress has been recently unraveled by showing that nSMase 2 is regulated by an intricate phosphorylation-based machinery (60). Specifically, nSMase 2 phosphorylation on specific serines causes both its activation and protein stabilization upon exposure of HAE cells to oxidative stress (56). In addition, some of the protein regulators of nSMase 2 phosphorylation were identified. For example, calcineurin $(\mathrm{CaN})$ phosphatase was shown to bind directly to nSMase2 (60). However, during $\mathrm{H}_{2} \mathrm{O}_{2}$-induced oxidative stress, $\mathrm{CaN}$ becomes inhibited by oxidation of its catalytic cysteine and is degraded, increasing nSMase2 phosphorylation and activity $(56,60)$.

\section{B. The surprising role of Src in controlling nSMase2/ ceramide generation}

The nonreceptor tyrosine kinase (RTK) Src is the first identified proto-oncogene, known for both its overexpression and overactivation in various cancers, including non-small cell lung cancer (NSCLC) $(73,202,236)$. In contrast, its role in injury-related pulmonary diseases remains unexplored. Several studies demonstrate that Src is activated by CS exposure in an oxidative stress-dependent manner $(57,118,119)$, under the conditions for which nSMase2-dependent ceramide generation and apoptosis induction were observed $(133,134)$. Therefore, it has been recently investigated whether Src activity mediates

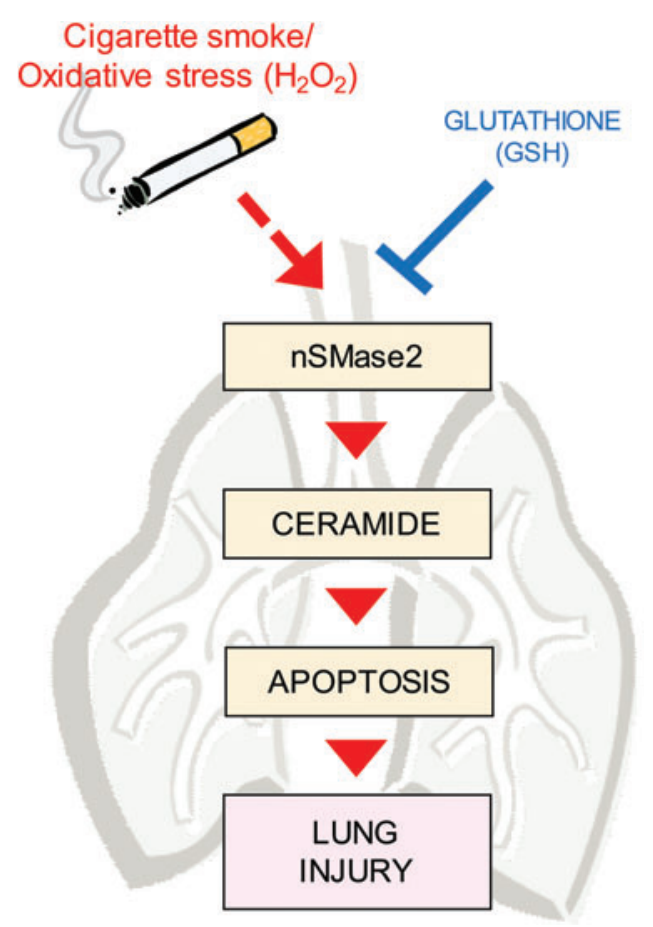

FIG. 2. The exposure of lungs to CS-induced oxidative stress upregulates both the expression and function of nSMase2. This enhances ceramide generation, which leads to lung cell apoptosis and subsequent lung injury [as published by Filosto et al. (57)]. nSMase2, neutral sphingomyelinase 2. CS, cigarette smoke. To see this illustration in color, the reader is referred to the web version of this article at www.liebertpub.com/ars 
nSMase 2 function and ceramide upregulation during CSinduced oxidative stress of HAE cells.

Surprisingly, it was found that Src indeed upregulates nSMase 2 activity and ceramide generation, via the intermediate p38 mitogen-activated protein kinase (MAPK), during oxidative stress exposure of HAE cells (29). Specifically, it was found upon direct $\mathrm{H}_{2} \mathrm{O}_{2}$ administration or CS-induced ROS generation (CS/oxidative stress) that inhibition of either Src or p38 MAPK suppresses nSMase2 activity, nSMase2 phosphorylation, and subsequent ceramide generation (29). Importantly, the oxidative stress-dependent activation of p38 MAPK occurs downstream of Src (29) (Fig. 3). It was previously shown by Clarke et al. (35) that p38 MAPK had some role in controlling nSMase 2 function. In addition, Schweitzer et al. also proposed a role for p38 MAPK as an upstream regulator of nSMase 2 and ceramide-dependent disruption of the lung epithelial-endothelial barrier (190). The studies by Chung et al. (29) add to these findings by demonstrating the unique role of Src in driving ceramide generation/accumulation during CS-induced oxidative stress. At the same time, a recent publication from Cinq-Frais et al. claims that Src can also be activated downstream of nSMase 2 and ceramide generation (33) in response to oxidative stress, which implicates the potential existence of a feedback loop that potentiates these signaling events.

Most importantly, as reported by Filosto et al. (59) and Petrache et al. (169), ceramide accumulation in alveolar cells is a dominant driver of smoking-related emphysema pathogenesis. Within this context, a recent article by Geraghty et al. (72) presented that Src inhibition in smoke-exposed mice prevented airspace enlargement in their lungs. Moreover, the same study showed that Src inhibition in HAE cells

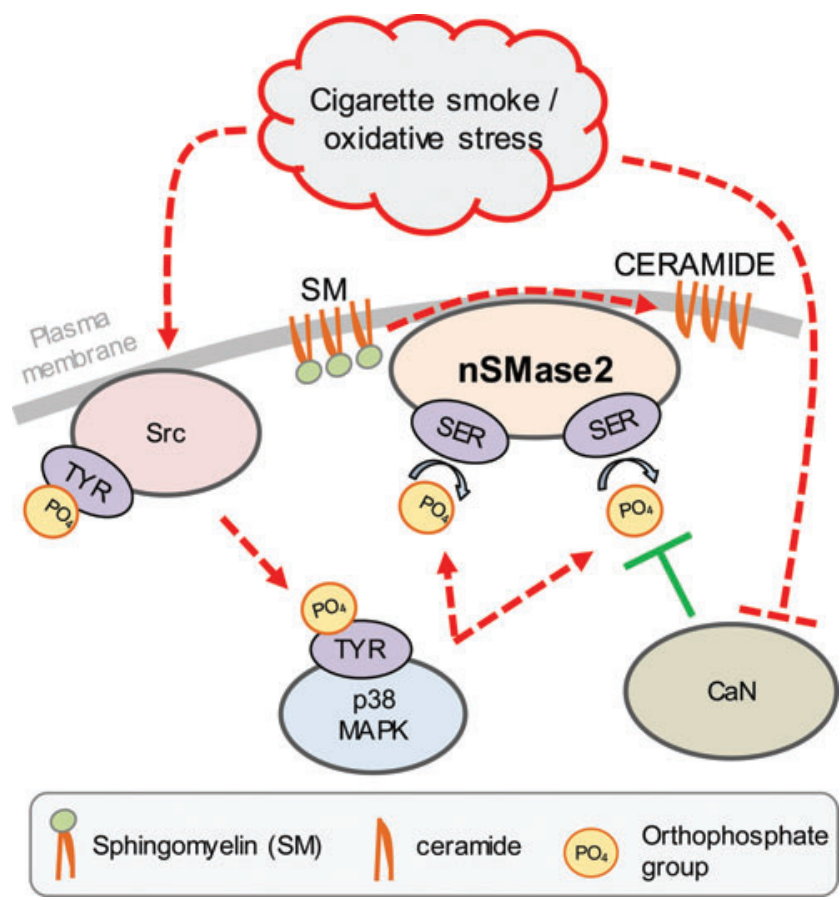

FIG. 3. Proposed mechanism for nSMase2 phosphorylation and activation downstream of Src activation under oxidative stress exposure. To see this illustration in color, the reader is referred to the web version of this article at www.liebertpub.com/ars prevented CS-induced signaling of EGFR, whose aberrant activation was suggested to be Src-related (57). This is very relevant to lung cancer development (as further described in Section VI). Thus, the potential involvement of Src, a known proto-oncogene, in the development of emphysema presents far reaching implications in the age-old conundrum of why smokers (active and former) are prone to both COPD and lung cancer development.

\section{Oxidative Stress and Lung Cancer}

Clinical epidemiology and anecdotal accounts have long revealed an intimate relationship between mainstream tobacco smoke exposure and development of lung cancer. Despite exhaustive preclinical and clinical studies investigating drivers of this disease, the prognosis of metastatic lung cancer still remains very poor with the 5-year survival rate hovering between $5 \%$ and $15 \%$ (110). However, recent progress has increased the understanding of key biological pathways in lung carcinogenesis $(37,86,100,187)$.

Localized chronic inflammation in the lung is observed in countless NSCLC patients. As discussed earlier in section II, the chronic nature of smoking-related inflammation in the lung results in remodeling of the extracellular matrix by protease release/activation, which not only encourages vascularization of the tissue but also promotes repair mechanisms, including epithelial cell proliferation-characteristics that are common and critical for various cancers (204).

At the same time, there are several classical and novel proto-oncogenes and onco-suppressors characterized in lung cancer, for which systematic understanding requires the reading of the referenced articles $(48,86,220)$. Within this section, we will specifically focus on two players: the EGFR and Src, which are highly activated in the lungs of COPD (70) and NSCLC patients (236) with smoking history and which become activated by CS in vitro and in vivo.

\section{A. Stress-driven endocytosis of tyrosine- phosphorylated EGFR leads to tumorigenesis: the critical role of oxidative stress}

The airway epithelium and the plasma membrane of its cells serve as the first barrier against native gaseous oxidants and particulate matter, species that are in extreme high levels in tobacco smoke. Although such exposure to tobacco smoke can initiate apoptotic pathways and trigger lung injury, as discussed above, it can also drive cell proliferation by its simultaneous stimulation of EGFR in airway epithelial cells $(80,177)$.

Seminal studies over the years demonstrated that the EGFR plays a prominent role in lung cancer development. Importantly, past reports have shown that cigarette smoking not only augments EGFR expression in human bronchial epithelium $(12,159,171)$ but also abnormally activates the receptor kinase (119) (Fig. 4). EGFR activation is thought to promote malignancy through its role in proliferation, angiogenesis, metastasis, and apoptosis inhibition. Although EGFR is expressed in all cells of epithelial origin, a higher level of EGFR expression has been reported in squamous cell carcinoma $(50 \%-80 \%)(99,100)$, which occurs more frequently in smokers and men (233). Moreover, EGFR overexpression is observed in tumors from more than $60 \%$ of patients with metastatic NSCLC and is correlated with poor prognosis (195). Although smoking has been established as the most important 

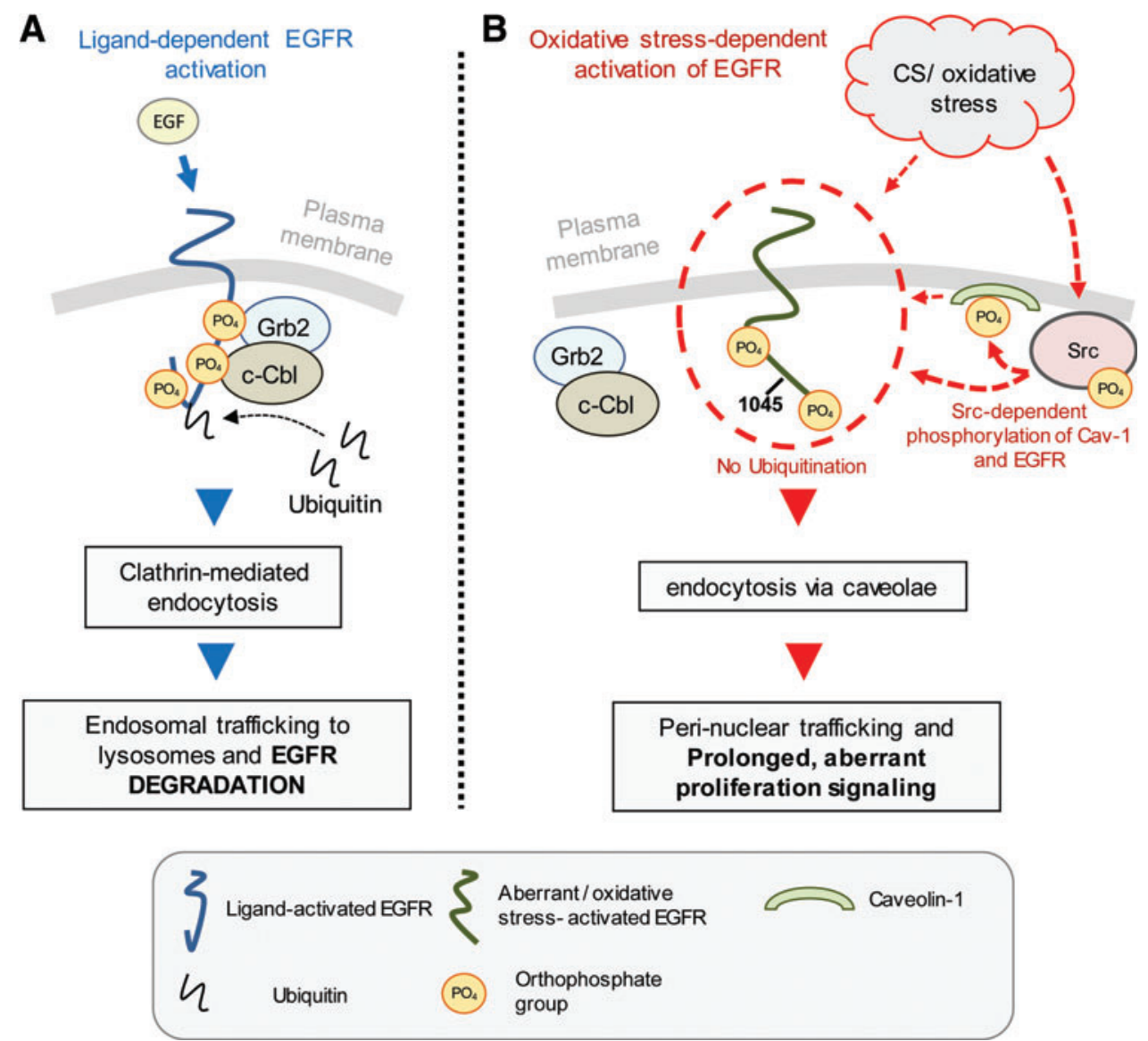

FIG. 4. (A) The canonic EGFR activation, endocytosis, and degradation and (B) the aberrant EGFR activation, endocytosis, and lack of degradation under CS/oxidative stress exposure. In (A), ligand binding to EGFR is followed by the canonical pattern of EGFR autophosphorylation, which includes Y1045 phosphorylation. This allows c-Cbl (and Grb2) binding, which results in receptor ubiquitination and internalization via the endo/lysosomal route. In (B), EGFR activation under oxidative stress does not result in phosphorylation of the Y1045, which hampers c-Cbl binding. In addition, the aberrant EGFR activation is accompanied by Src activation and its strong binding to the receptor; Src phosphorylates both EGFR (at Tyr-845) and Cav-1 at Tyr-14, which leads to Cav-1 association with EGFR and subsequent caveolae-dependent endocytosis of EGFR. The EGFR then traffics to a perinuclear region, where it remains active. c-Cbl, cellular-casitas Blineage lymphoma; EGFR, epidermal growth factor receptor; Cav-1, caveolin-1; Grb2, growth factor receptor-bound protein 2. To see this illustration in color, the reader is referred to the web version of this article at www.liebertpub.com/ars

preventable cause of lung cancer, it has been recently demonstrated that somatic mutations of the EGFR are responsible for $\sim 10 \%-25 \%$ of all nonsmoking-related lung cancer cases $(153,165)$. These findings have since provided rationale for the development of EGFR-targeted and now Food and Drug Administration (FDA)-approved cancer therapeutics known as tyrosine kinase inhibitors (TKIs).

More than 3 decades of research have established a fairly defined mechanism of EGFR activation, internalization, and subsequent downregulation upon ligand (EGF) binding to the receptor extracellular domain. However, much less is known about the ligand-independent mechanisms of EGFR activation and trafficking. These "alternative" mechanisms can generate a hallmark of severe human pathological conditions, particularly in cancer, and thus defining them is extremely relevant to the mission of understanding and fighting against EGFR-driven tumorigenesis.

1. Canonical EGFR activation, intracellular trafficking, and degradation. The EGFR (ErbB1) is a member of the ErbB family of RTKs, which also includes ErbB2, ErbB3, and ErbB4. These receptors have a vital role in normal cellular processes, such as cell division, differentiation, and migration, and their overexpression or deregulation has been linked to a variety of human cancers $(189,231,232)$. Hence, their activation, particularly that of the EGFR, has been a subject of intense studies.

The model of EGFR activation has been established wherein ligand binding induces receptor dimerization, leading to the activation of its intrinsic tyrosine kinase activity, autophosphorylation, and subsequent phosphorylation of downstream signaling molecules $(188,189)$ involved in cellular survival and proliferation. Upon EGF binding, the EGFRs are rapidly internalized from the cell surface through numerous pathways, including clathrin-coated pits (219). Therefore, to control cellular growth and tumorigenesis, the activation of the EGFR has to be tightly regulated in a process that includes degradation of the receptor. Indeed, the inability of the EGFR to be downregulated via clathrin-mediated endocytosis and degradation has been linked to its oncogenicity (64). 
Although the exact mechanism by which the EGFRs are recruited into the clathrin-coated pits is under investigation, the general paradigm of EGFR internalization is as follows. The EGF-activated EGFRs recruit growth factor receptorbound protein 2 (Grb2), which plays a critical role in the binding of adaptor protein 2 complex (AP-2) $(103,111)$. AP2 subsequently recruits clathrin (cytosolic scaffold protein that mediates vesicle formation) to the plasma membrane, which polymerizes to form a clathrin coat that provides the framework required for vesicular budding into the cell and eventual internalization of the activated EGFRs (170).

Internalized RTKs, such as the EGFR, undergo a general modulatory phase consisting of a two-step endocytosis process $(86,142,219,221)$ : (1) A fast ligand-dependent internalization step removes activated receptors from the cell membrane and segregates them in endosomes, followed by either (2) sorting of internalized RTK molecules to lysosomes, where they go through degradation, or recycling back to the plasma membrane. Notably, EGFR classified for lysosomal degradation requires the recruitment of cellular-casitas B-lineage lymphoma (c-Cbl), which controls EGFR ubiquitination (132). Expectedly, molecular studies impeding clathrin-mediated endocytosis resulted in no subsequent lysosomal degradation of the ligand-activated EGFR $(106,160,188)$. This could maintain prolonged downstream activation of prosurvival and proliferation molecules, such as Akt and extracellular regulated protein kinase (ERK1/2) (71), thereby enhancing cell proliferation and tumorigenesis (42).

2. CS produces $\mathrm{H}_{2} \mathrm{O}_{2}$-induced oxidative stress that aberrantly activates EGFR. Since $\mathrm{H}_{2} \mathrm{O}_{2}$ is known to be a major component of the gas phase of CS (157), a study was undertaken by Khan et al (119) to determine whether CS has a similar effect as $\mathrm{H}_{2} \mathrm{O}_{2}$ on EGFR activation in HAE cells, which included primary immortalized and transformed cells.

First, it was demonstrated that CS could generate comparable amounts of $\mathrm{H}_{2} \mathrm{O}_{2}$ that were generated in previous experiments. These earlier studies used artificially produced $\mathrm{H}_{2} \mathrm{O}_{2}$ by complementing the cells with high glucose media and glucose oxidase (GO) $(118,176,177)$. Next, it was not only shown that CS can activate the EGFR in a dose- and time-dependent manner but also that it aberrantly phosphorylated the receptor with a pattern of phosphorylation sites that was different from that induced by the ligand, EGF, but identical to the phosphorylation pattern induced by GO (namely $\mathrm{H}_{2} \mathrm{O}_{2}$ ). Moreover, the EGFR was not activated and very little or no $\mathrm{H}_{2} \mathrm{O}_{2}$ could be detected in cell culture medium exposed to CS in the presence of GSH (119), an antioxidant that targets reactive radicals, including ROS, such as $\mathrm{H}_{2} \mathrm{O}_{2}$ (91). This demonstrates that the oxidative stress component of CS was necessary for the activation of EGFR in HAE cells exposed to CS. Notably, Ganesan et al. recently presented an aberrantly activated EGFR receptor in COPD patients (70). Moreover, Geraghty et al. demonstrated in mice exposed to CS that the proto-oncogene Src promoted the EGFR activation in the airway epithelium, thereby enhancing airway inflammation and lung tissue destruction (72). These findings attempted to provide an acceptable mechanism connecting the molecular origins of COPD and lung cancer.

Several in vitro reports demonstrated the inactivation of protein tyrosine phosphatases (PTPs) by $\mathrm{H}_{2} \mathrm{O}_{2}$ and thus suggested that this was the cause responsible for EGFRenhanced tyrosine phosphorylation under oxidative stress (46, 69, 76, 131, 227). For example, data published by Xu et al. indicated that $\mathrm{H}_{2} \mathrm{O}_{2}$ induced phosphorylation of EGFR on Y1068 while PTPs activity was reduced to $\sim 70 \%$ of control. Although PTPs inactivation certainly contributes to the enhanced phosphorylation of EGFR upon $\mathrm{H}_{2} \mathrm{O}_{2}$ exposure, Khan et al. and Reynolds et al. showed that $\mathrm{H}_{2} \mathrm{O}_{2}$ could not induce phosphorylation of a kinase-dead EGFR $(118,181)$, suggesting that the kinase activity of the receptor is also required for its activation/phosphorylation by $\mathrm{H}_{2} \mathrm{O}_{2}$. In addition, the sole inactivation of PTPs cannot explain the change in the pattern of EGFR tyrosine phosphorylation. It was reported that under both CS-induced $\mathrm{H}_{2} \mathrm{O}_{2}$ and direct $\mathrm{H}_{2} \mathrm{O}_{2}$ exposure, the display of EGFR phosphorylation sites differs from that induced by EGF binding to the receptor. Particularly, EGFR tyrosine (Tyr) Y845 is robustly phosphorylated under $\mathrm{H}_{2} \mathrm{O}_{2}$ or CS exposures, whereas Y1045 phosphorylation is totally absent. This ultimately results in an active EGFR that is unable to undergo normal downregulation, demonstrating impaired trafficking and degradation. More explicitly, upon $\mathrm{H}_{2} \mathrm{O}_{2}$-induced oxidative stress, the aberrantly activated EGFR is unable to bind $\mathrm{c}-\mathrm{Cbl}$ and thus is neither ubiquitinated nor targeted to lysosomes for degradation. Instead, EGFR is strongly associated with the phosphorylated caveolin-1 (Cav-1) in an Src-dependent manner and thus is recruited into caveolae and not into clathrin-coated pits $(76,118,119,176,177)$. Such oxidative stress-dependent impairment of the EGFR clathrinmediated endocytosis and lysosomal degradation (106, $160,188)$ results in prolonged downstream activation of prosurvival and proliferative signals, such as of Akt and ERK1/2 (71). This coincided with enhanced cell proliferation (215) and was shown to facilitate tumor promotion processes in the epithelial cell line T51B (105) as well as to mediate tumor promotion in other nonneoplastic rat liver epithelial cells (42).

Intriguingly, a previous report by Bae et al. indicated that the ligand, EGF-induced EGFR phosphorylation, required the presence of intracellular $\mathrm{H}_{2} \mathrm{O}_{2}$. Overexpression of catalase could quench the receptor canonical activation/phosphorylation by EGF. However, the $\mathrm{H}_{2} \mathrm{O}_{2}$ generation itself appeared to be EGFR kinase dependent because it was abolished in the presence of a kinase-dead EGFR (10). Conversely, Ushio-Fukai et al. (214) showed no effect of the antioxidant, NAC, on EGF-stimulated activation of EGFR. These authors also claimed that angiotensin II-dependent transactivation of EGFR was the one dependent on ROS generation and was indeed abolished in the presence of the antioxidant NAC (214). The use of different cell types can partially explain the discrepancies in the findings of various studies carried out by different groups; however, one can also speculate that while a local and transient generation of $\mathrm{H}_{2} \mathrm{O}_{2}$ has a physiological role in the ligand-initiated signaling, a pathological imbalance in the cell redox potential due to enhanced $\mathrm{H}_{2} \mathrm{O}_{2}$ accumulation can lead to an aberrant EGFR activation accompanied by an abnormal downstream signaling. In line with this idea, Reynolds et al. (181) also demonstrated a $\mathrm{H}_{2} \mathrm{O}_{2}$-dependent inactivation of PTPs as one of the mechanisms inducing EGFR lateral mobility at the plasma membrane and subsequent amplification of the receptor phosphorylation and signaling (181). In addition, the 
same study suggested that the $\mathrm{H}_{2} \mathrm{O}_{2}$ produced physiologically in response to EGF stimulation may have a different cellular localization compared to the $\mathrm{H}_{2} \mathrm{O}_{2}$ generated pathologically by environmental causes. The first was described as spatially constrained to a layer below the plasma membrane (181), whereas the latter, the exogenously administrated $\mathrm{H}_{2} \mathrm{O}_{2}$, is also found in the endomembranes, which could be one of the reasons for its aberrant pathological effects. Of note is that the "physiological" $\mathrm{H}_{2} \mathrm{O}_{2}$ was never observed in the endomembranes.

Altogether, the above findings indicate that the exposure of cell to pathological $\mathrm{H}_{2} \mathrm{O}_{2}$ /oxidative stress could induce nonligand-bound EGFR phosphorylation based on both EGFR aberrant kinase activation and PTPs inhibition. Moreover, such oxidative stress-driven EGFR phosphorylation/signaling is not restricted to the plasma membrane compartment.

As discussed, $\mathrm{H}_{2} \mathrm{O}_{2}$ can affect both the EGFR kinase itself and other EGFR regulators, including the PTPs. Therefore, to gain more insight into $\mathrm{H}_{2} \mathrm{O}_{2}$-induced EGFR signaling and hyperplasic responses, the role of the E3 ligase c-Cbl, as a possible link between oxidative stress, EGFR signaling, and tumorigenesis, was further examined.

3. The lack of $\mathrm{c}-\mathrm{Cb}$ binding to EGFR causes prolonged proliferation signaling under oxidative stress. It was well established that upon EGF stimulation of cells, c-Cbl binds directly to the EGFR via Tyr-1045 (176) and indirectly through the SH3 domain of Grb2 (66). c-Cbl binding and its consequential phosphorylation results in the activation of the E3 ligase activity of c-Cbl, recruitment of the ubiquitin-conjugating enzyme Ubc-H7 (234), and EGFR ubiquitination.

On the other hand, upon mapping the EGFR phosphorylation sites, it was found that phosphorylation at Tyr-1045, the docking site for c-Cbl (132), was abrogated under oxidative stress, and thus, the receptor could not be ubiquitinated and degraded. Therefore, it was suggested that this deficiency might have a key role in linking oxidative stress, the EGFR, and tumorigenesis by conferring prolonged receptor signaling (177).

To gain a better understanding of how a receptor lacking c$\mathrm{Cbl}$ binding may lead to tumorigenesis, the mutant EGFR (Tyr-1045 to Phe) was ectopically expressed in CHO cells to determine whether the lack of phosphorylation at this site is indeed the only cause for prolonged EGFR retention at the membrane under oxidative stress. However, additional findings suggested that the inability of the EGFR to bind c-Cbl under oxidative stress is not solely due to its abrogated Tyr1045 phosphorylation because the Y1045F mutant was still able to bind c-Cbl, probably indirectly via Grb2 (176).

Indeed, other studies suggested that $\mathrm{c}-\mathrm{Cbl}$ is recruited to the activated EGFR through both direct and indirect binding $(112,218)$. It has been shown that the direct interaction of $\mathrm{c}-\mathrm{Cbl}$ with EGFR is mediated through the phosphorylated Tyr-1045 on EGFR (132), whereas the indirect c-Cbl-EGFR interaction is maintained via $\mathrm{SH} 2 / \mathrm{SH} 3$ Grb2 domains (67, 111). Consistently, Huang and Sorkin (104) reported that knockdown of Grb2 by RNA-interference inhibited clathrinmediated endocytosis of the EGFR after EGF exposure of the cells because of the impaired recruitment of the c-Cbl RING domain to EGFR. Of note is that the two binding sites of Grb2 to the EGFR, Tyr-1068 and Tyr-1086, are phosphorylated under $\mathrm{H}_{2} \mathrm{O}_{2}$ exposure, but $\mathrm{Grb} 2$, which is still bound to $\mathrm{c}-\mathrm{Cbl}$, does not bind the EGFR. Furthermore, Shc, whose phosphorylation and binding to Grb2 had been shown to be responsible for Grb2 recruitment to the EGFR (111), is still phosphorylated under $\mathrm{H}_{2} \mathrm{O}_{2}$ exposure and is still able to bind to the EGFR. Therefore, most possibly Grb2 fails to bind to the EGFR under oxidative stress exposure due to conformational changes in the EGFR. Consistently, Goldkorn and colleagues $(58,61)$ have shown that oxidative stress induces a novel active kinase conformation of the receptor, which is described in detail below in section IV.A.5.

Undoubtedly, the studies with the Y1045F mutant (MT) EGFR (176) led to a better understanding of why c-Cbl fails to bind to the EGFR under oxidative stress, which is due to both the abrogation of phosphorylation of Tyr-1045 and the lack of Grb2 binding, thereby resulting in a receptor unable to undergo normal internalization through the early endosomes and subsequent downregulation (176) (Fig. 4).

When is c-Cbl actually required for EGFR sorting? Early on, several studies led to some confusion about when and where $\mathrm{c}-\mathrm{Cbl}$ is required for EGFR internalization, as well as the role of EGFR Tyr-1045 phosphorylation in c-Cbl recruitment. For example, Jiang and Sorkin (112) showed data suggesting that the Y1045F EGFR MT was internalized despite its inability to undergo ubiquitination, whereas Mosesson et al. (151) demonstrated that the Y1045F MT is internalization-resistant. At the same time, Duan et al. (51) showed in $\mathrm{c}-\mathrm{Cbl}^{-/-}$mouse embryonic fibroblasts that the EGFR could still be internalized following EGF stimulation.

To gain a better understanding of the consequences of EGFR inability to recruit c-Cbl under oxidative stress, the exact cellular compartment where c-Cbl-mediated ubiquitination is necessary for EGFR sorting was investigated. In particular, Ravid et al. showed (176) that the administration of PP1 (an Src family kinase [SFK] inhibitor) to A549 cells blocked the EGF-induced phosphorylation of c-Cbl (but not of the EGFR) and the ubiquitination of the EGFR, without inhibiting the internalization of the receptor into early endosomes. Notably, an efficient binding of c-Cbl to the EGFR was observed upon EGF stimulation in the presence of PP1 (in both wild-type [WT] and Y1045F MT receptors), which implies that the tyrosine phosphorylation of $\mathrm{c}-\mathrm{Cbl}$ is not required for its binding to the EGFR or for its role in the entry of EGFR into the early endosomes. At extended time points of cells treated with PP1 and EGF, the EGFR remained associated with EEA1, an early endosome marker. Only after PP1 removal and the subsequent recovery of c-Cbl phosphorylation and EGFR ubiquitination, EGFR could exit from the early endosomes. Therefore, it was concluded that the c-Cbldependent ubiquitination is required for the exit of EGFR from the early endosomes.

In summary, the major findings of that study (176) were that $\mathrm{c}-\mathrm{Cbl}$ binding to the EGFR is sufficient to enhance receptor internalization, whereas the E3 ligase activity of c-Cbl and EGFR ubiquitination are required for EGFR trafficking out of the early endosomes and eventual transport to the lysosome for the degradation of the receptor. In addition, that study also suggested that the EGFR lack of Tyr-1045 phosphorylation during exposure to oxidative stress is not the only reason for the receptor inability to enter the late endosomes. Rather, the role of Grb2 in the recruitment of $\mathrm{c}-\mathrm{Cbl}$ as an adaptor added an additional level of complexity to the mechanism of EGFR sorting under oxidative stress. 
Importantly, the degree of intricacy was further expanded by other studies that demonstrated that several proteins with ubiquitin interaction domains are in fact required for EGFR transfer from the early endosomes to other vesicular bodies for degradation $(11,213)$. For example, the proteins Hrs and Tsg 101 were shown to be involved in a large sorting complex that is "somehow" responsible for coupling EGFR transfer between early and late endosomes. Although the detailed mechanism has yet to be identified, one can imagine a situation where this large protein sorting complex binds to the ubiquitinated EGFR, thus allowing its transfer into the late endosomes.

4. EGFR perinuclear sorting under oxidative stress. In light of the above studies, the next question was how the EGFR is specifically sorted under oxidative stress. Another study (118) suggested that, under oxidative stress, EGFR is able to undergo clathrin-independent endocytosis and is sorted to a perinuclear compartment, where it is not degraded and remains active. The mechanism of this trafficking involves Src activation by $\mathrm{H}_{2} \mathrm{O}_{2}$-induced oxidative stress, which subsequently phosphorylates Cav-1 at Tyr-14 and triggers the caveolar endocytosis of EGFR (Fig. 4).

Cav-1 and Cav-2 heterooligomerize and form caveolae, which are integrated into the lipid rafts $(63,68,128,156$, 172). It has been suggested that Cav-1 can function in caveolae in a manner analogous to the way clathrin adaptors draw membrane receptors to coated pits and/or drive membrane invagination and budding (172). Cav-1 is known to interact directly with many signaling molecules through its caveolin-scaffolding domain at residues 82-101 $(38,107)$. Indeed, EGFR has been reported to interact with the caveolinscaffolding domain through a caveolin-binding sequence motif located in the intracellular kinase domain (residues $898-905)$ of the receptor $(39,107)$. To elucidate the mechanism by which EGFR is being trafficked to the perinuclear compartment under oxidative stress, the involvement of Cav-1 was investigated.

Expressing a WT Cav-1 or a Tyr-14 MT (Y14A) Cav-1 in a cell culture model, it was demonstrated that EGFR is constitutively associated with Cav-1. However, Cav-1 is phosphorylated on $\mathrm{Y} 14$ only in the presence of $\mathrm{H}_{2} \mathrm{O}_{2}$ and is subsequently accumulated together with EGFR in the perinuclear compartment. When either Src was inhibited or when the Y14A Cav-1 MT was overexpressed, the accumulation of EGFR was not observed at that unusual site (118).

Despite some reports that several SFKs are involved in oxidative stress-induced phosphorylation of Cav-1 $(19,185)$, the observation that EGFR Tyr-845, a c-Src target (16), is robustly phosphorylated under oxidative stress suggests that c-Src involvement is not coincidental. Consistently, Dittmann et al. have recently described a radiation-induced mode of EGFR trafficking to the nucleus, and the specific knockdown of c-Src (by siRNA) blocked EGFR phosphorylation at Y845 as well as the phosphorylation of Cav-1 at Y14 and resulted in the blockade of EGFR transport into the nucleus (49). It should also be noted that Sanguinetti and Mastick (186) have reported that c-Abl (Abelson murine leukemia viral oncogene homolog) kinase expression is required for oxidative stress-induced phosphorylation of Cav-1, although its eventual role in the perinuclear sorting of EGFR remains to be determined.
Although the above study (118) demonstrated that Srcmediated phosphorylation of Cav-1 Tyr-14 was necessary for caveolar endocytosis of EGFR under oxidative stress, the exact role of Cav-1 remains to be determined. Pelkmans et al. (167) suggested that the manner in which caveolar cargo is taken up and released depends on how the cargo interacts with Cav-1 as well as with other caveolar proteins and on how the cargo is influenced by compartment-specific signals, such a $\mathrm{pH}$ changes. The model thus far (118) indicates that $\mathrm{H}_{2} \mathrm{O}_{2}$ activation of EGFR results in aberrant receptor phosphorylation that precludes it from being sorted through clathrincoated pits for eventual lysosomal degradation (176, 177). Concomitantly, $\mathrm{H}_{2} \mathrm{O}_{2}$ (but not EGF) activates c-Src, which in turn phosphorylates Cav-1 at Y14 (a proposed trigger for caveolar endocytosis) and also dynamin-2 (at Y231/Y597), which is thought to localize at the neck of caveolae such that the stimulation of its GTPase activity leads to vesicle fission $(161,193,194)$. Through this route of caveolar endocytosis, $\mathrm{H}_{2} \mathrm{O}_{2}$-activated EGFR is trafficked to a perinuclear region where continued receptor signaling is identified via Tyr-1173 phosphorylation, potentially contributing to prolonged proliferative signaling $(61,118)$ and tumorigenesis.

5. An aberrant activated conformation of EGFR under oxidative stress underlies lung cancer resistance to targeted therapy. The well spent effort to better understand the mechanisms of EGFR kinase activation was aimed to develop specific inhibitors, such as the TKIs. To date, several TKIs, erlotinib (Tarceva ${ }^{\mathrm{TM}}$ ) and gefitinib (Iressa ${ }^{\mathrm{TM}}$ ), are approved by the FDA for the treatment of metastatic lung cancer driven by the expression of oncogenic mutant EGFR while several second-generation TKIs are in clinical trials (e.g BIBW2992) or in various phases of drug development $(55,87,217,225)$.

Importantly, clinical use of TKIs is effective in a subset of lung cancer patients who express oncogenic, but also TKIsensitive, EGFR mutations-exon 19 deletion $(\Delta 746-750)$ and exon 21 single-point substitution mutation (L858R) (153, 165). Despite being first identified by its prevalence in NSCLC patients who were women of Southeast Asian origin and nonsmokers, it is important to note that the expression of the mutant EGFRs itself confers sensitivity to TKI therapy.

Interestingly, however, D'Angelo et al. have recently found that a significant number $(40 \%)$ of those EGFR mutations (L858R and $\Delta 746-750$ ) are actually found in adenocarcinoma from both men and women who are current and former smokers (41). Although it is generally accepted that patients who are smokers do not benefit from TKI therapy, we still do not know whether lung cancer patients who carry the "TKI-sensitive" EGFR mutations and are former/current smokers would benefit from a TKI therapy (in comparison to those who are neversmokers). This is because those patients (harboring TKI-sensitive EGFR mutations and being smokers) were not rigorously screened and tested in any clinical trial assessing TKI effectiveness. Moreover, a recent anecdotal observation illustrated how patients responsive to TKI therapy acquire resistance to TKIs if they began smoking (Lara PN, personal communication, 2012).

Consistently, recent cellular studies on smoking-induced redox signaling and its impact on epithelial cell proliferation and tumorigenesis demonstrated that smoking-induced oxidative stress can indeed affect the sensitivity to TKIs therapy of both WT and oncogenic mutant EGFR overexpressing NSCLC cells $(57,58)$. 
As described earlier, CS/oxidative stress activation of EGFR was found to be ligand-independent, did not induce "classical" receptor dimerization and was not inhibited by the TKIs AG1478, erlotinib (Tarceva) and gefitinib (Iressa) $(58,61)$. Thus, an unprecedented activated state of EGFR was described under oxidative stress. This activation mechanism was also shown to be temperature-dependent, suggesting the simultaneous involvement of the cell membrane state of fluidity (61).

Supporting these findings, an in vitro study by Burdick et al. presented only a partial reduction of EGFR phosphorylation by the TKI AG1478 following the exposure of breast cancer cells to $\mathrm{H}_{2} \mathrm{O}_{2}$ (18). Conversely, a previous report from Takeyama et al. claimed that the TKI AG1478 is effective against EGFR activation induced by CS (206). However, the technical conditions utilized by Takeyama et al. significantly differed from those used in the studies of Filosto et al. $(57,58)$. Takeyama's study used CS condensate/solution, whereas Filosto's study employed direct exposure of cells to the gas phase of CS (CS puffs) (58). In addition, Takeyama's study involved high concentrations $(10 \mu M)$ of the TKI AG1478 without presenting any dose-response curves and without any data on the consequential EGFR phosphorylation. However, Takeyama's conclusions are supported, to some extent, by Hirota et al. studies (98). This group could observe a redox-sensitive (NAC-inhibited) transactivation of EGFR by TNF- $\alpha$ stimulation of NIH3T3 cells, which could be inhibited by $50-250 \mathrm{nM}$ AG1478 TKI (98). Yet, these studies not only used fibroblasts (as opposed to lung epithelial cells) but also never exposed these cells directly to $\mathrm{CS} / \mathrm{H}_{2} \mathrm{O}_{2}$ or to $\mathrm{CS} / \mathrm{H}_{2} \mathrm{O}_{2}$ in the presence and absence of AG1478.

As concluded before (section IV.A.2), diverse outcomes could be typically expected in studies, carried out in different cells. Another important factor that may contribute to disparate results in EGFR signaling outcomes is the slightly dissimilar experimental conditions, which may lead to distinct cellular localization of the receptor. For example, the responses of EGFR under physiological concentrations of $\mathrm{H}_{2} \mathrm{O}_{2}$, which are strictly localized to the plasma membrane, are expected to significantly differ from responses under pathological higher concentration of $\mathrm{H}_{2} \mathrm{O}_{2}$ exposures, which could be diffused throughout the cell.

Recent data from Chung et al. (27), as well as from studies by Bublil et al. (17), demonstrated that EGFR does not need an extracellular ligand to form dimers. EGFR continuously changes from a monomer to a dimer state, where the interactions between the intracellular domains of the receptor are as important as those of the extracellular regions in forming dimers. These recent findings underlie the need for better understanding the mechanisms involved in ligand-independent activation of EGFR and the physiological relevance of such mechanisms.

Very important indication that EGFR exposed to oxidative stress undergoes a unique conformational change was supported by the finding that under such conditions, EGFR could strongly bind c-Src. Moreover, the interaction between EGFR and c-Src was not dependent on the activation of c-Src because it persisted even in the presence of the c-Src kinase inhibitor, PP1 $(57,58,61)$. Additionally, Kim et al. reported that under physiological conditions, c-Src could stably interact with ErbB2, but not with EGFR (ErbB1), because of the structural differences between ErbB1 and ErbB2 in the kinase domains of the two receptors (120). Consistently, studies with the L858R EGFR MT also demonstrated that this MT could bind c-Src, whereas the WT EGFR under physiological conditions could not. The L858R EGFR MT was crystallized and shown to possess a protein conformation that differs from that of the WT EGFR at the level of the kinase domain, carrying a constitutively open "activating-loop" (237). Interestingly, the L858R EGFR MT was also shown to have a similar functional phenotype to that of the WT EGFR exposed to oxidative stress, previously described by Goldkorn and colleagues (118, 176, 177). These unique features included prolonged phosphorylation/activation, lack of Y1045 phosphorylation followed by lack of ubiquitination, impaired trafficking and degradation, and constitutive interaction with c-Src, without any ligand stimulation $(25,26$, 163, 196) (Fig. 5). This further supported the idea that $\mathrm{H}_{2} \mathrm{O}_{2}$ induces a conformational change in the intracellular kinase domain of EGFR. Accordingly, dimerization of the extracellular domain could not be captured by the EDAC [1-ethyl3- (3-dimethylaminopropyl) carbodiimide] cross-linker neither for the WT EGFR under oxidative stress $(58,61)$ nor for the L858R MT.

Intriguingly, although WT EGFR under CS/oxidative stress appears to acquire a novel activated conformation, that conformation seemed to be different from that of the L858R EGFR MT, which is known to be sensitive to TKIs (229). This was shown by employing a novel anti-EGFR antibody $(\alpha 4-2 \mathrm{mAb})(58,61)$ that is susceptible to the conformational changes induced by EGF binding to the receptor (108) or by the somatic mutation L858R. It was proven that $\mathrm{CS} / \mathrm{H}_{2} \mathrm{O}_{2}$-generated oxidative stress induced a unique active conformation of the receptor $(58,61)$, which is different from that of both the EGF-induced WT EGFR and the L858R EGFR MT (Fig. 6). Furthermore, this distinctive conformation/activation mechanism appeared to be also temperature-dependent, suggesting the simultaneous involvement of changes in the membrane structure (61), as further discussed later on in section VII.E.

The above findings have important clinical implications in that the oxidative stress-activated EGFR cannot be inhibited by TKIs in NSCLC and may explain the ineffectiveness of these drugs in NSCLC patients with smoking history (58). Furthermore, aberrant EGFR activation has been recently shown by others to occur in the lungs of COPD patients (70, 223), who present chronic pulmonary oxidative stress (175), and, as mentioned above, have high risk for developing lung cancer (103). In addition, and very importantly, the protooncogene Src and its activation has been recently implicated in supporting the TKI-resistant conformer of EGFR (57), as described and reviewed in detail in section VI.

\section{Smoking and Lung Diseases: The Enigmatic Association Between Lung Injury and Lung Cancer}

Several prospective clinical studies have shown that lung cancer incidence is significantly increased in COPD patient populations (103). For instance, de Torres et al. reported that in their 5-year prospective cohort of former and current smokers, individuals with emphysema were more likely to develop lung cancer than those without emphysema (43): even the existence of some low-grade emphysema without noticeable airflow obstruction is associated with significantly 
A

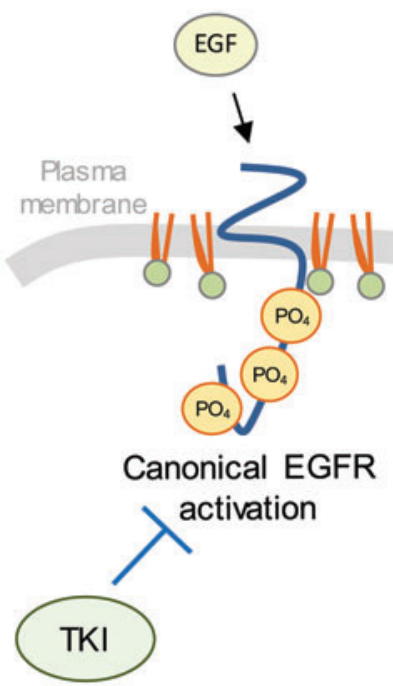

B

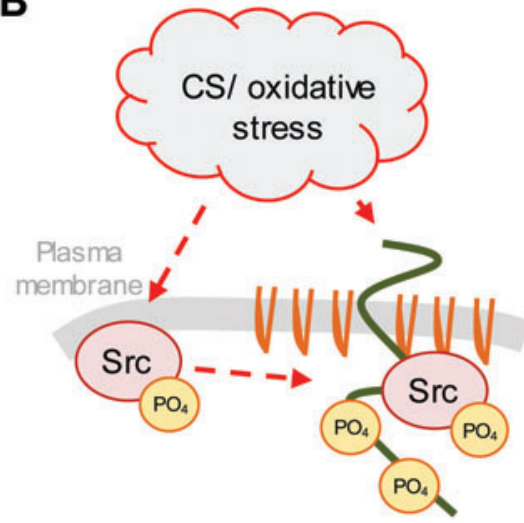

Aberrant EGFR $\because{ }^{\text {activation }}$

TKI

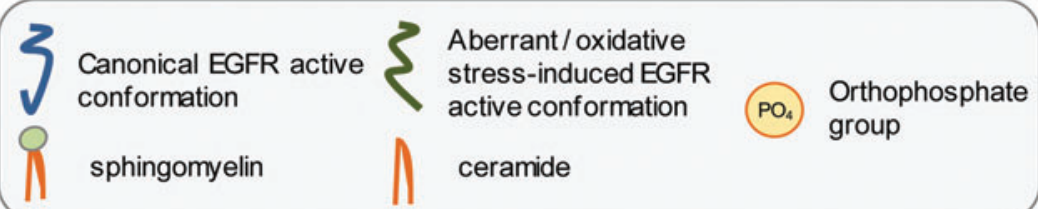

A
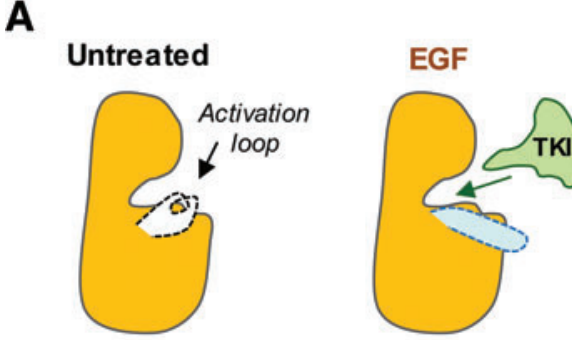

Inactive

WT EGFR kinase

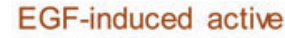

WT EGFR kinase conformation

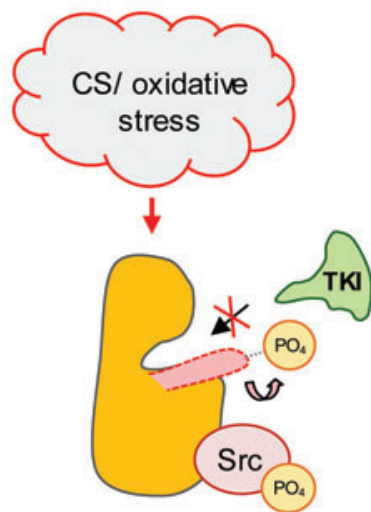

CS-induced Aberrant conformation, Resistant to TKI

: B

\section{L858R - MT}

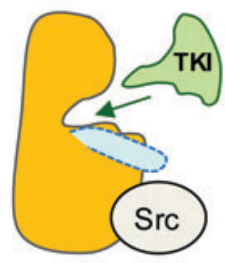

L858R MT EGFR

Active conformation

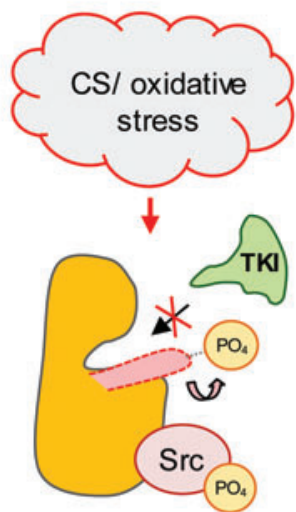

CS-induced Aberrant conformation, Resistant to TKI
FIG. 5. General model of (A) the canonical EGF-activated EGFR conformation compared to $(\mathrm{B})$ the aberrant active conformation of EGFR induced by CS/ oxidative stress and its subsequent resistance to TKIs. TKIs, tyrosine kinase inhibitor(s). To see this illustration in color, the reader is referred to the web version of this article at www.liebertpub.com/ars
FIG. 6. Proposed model of Src activation affecting EGFR kinase conformation and sensitivity to TKI drugs during exposure to CS/oxidative stress of (A) WT EGFR and (B) L858R EGFR. WT, wild type. To see this illustration in color, the reader is referred to the web version of this article at www.liebertpub.com/ars 
elevated risk of lung cancer. Individuals with both emphysema and airway obstruction were at even higher risks than those with neither condition (43). Since the identification of mechanisms linking COPD and lung cancer has long been hampered by the heterogeneity of the disorders, it is still not known whether emphysema confers a local-regional risk for lung cancer or a global one (103).

Therefore, the clinical data may require a novel mechanistic understanding of how apoptosis-dependent lung injury may lead to cell proliferation-dependent lung cancer. Indeed, albeit originated by opposing cellular phenotypes (programmed cell death $v s$. cell proliferation), the two diseases may actually share some common cell signaling events. Numerous studies address these questions at various levels, such as genetic susceptibility, extracellular matrix/proteases, and inflammatory cells in the field of injury (103). Within this context, we herein describe in detail the novel example of the role of Src and the ceramide-generating machinery induced by CS-generated oxidative stress, as a possible signaling complex that regulates both epithelial lung injury and lung cancer as well.

\section{The Dichotomous Response of Airway Epithelial Cells to CS Oxidants: A Critical Role for Src}

During CS-induced oxidative stress, Src plays a dichotomous role in airway epithelial cells (79). On one hand, ceramide, a "proapoptotic" sphingolipid, is generated by the induction of nSMase2 activity downstream of Src (29). On the other hand, the EGFR becomes aberrantly activated with the support from Src, promoting proliferative signaling and resistance to cancer therapy.

Src, the first proto-oncogene described, has previously been observed to be redox-sensitive, becoming activated by exogenous $\mathrm{H}_{2} \mathrm{O}_{2}$ (61) and $\mathrm{CS}$ (58). Owing to this shared stimuli between Src activation and CS-induced ceramide generation in HAE cells, unanticipated evidence was recently provided, demonstrating that Src activation upon CS/oxidative stress exposure controls nSMase2 function and subsequent ceramide generation at the plasma membrane of HAE cells (29), an accepted hallmark of apoptosis induction and lung injury $(56,59,60,114,190)$.

At the same time, Src is a known key participant in the EGFR family pathway. Phosphorylation of several tyrosine residues within the EGFR has been shown to be increased following Src overexpression both in vitro and in vivo, indicating that $\mathrm{Src}$ is needed for full biological response following EGF stimulus $(137,208)$. Furthermore, using chimeric EGFR/ ErbB2 receptors $(137,141)$, it was demonstrated that Src specifically binds to ErbB2, but not to WT EGFR or other ErbB family members. However, mutant EGFRs isolated from lung adenocarcinomas have the capacity to bind to Src, and these EGFR mutants require Src kinase activity for transformation $(25,141)$.

Recent in vitro studies of NCLSC cells exposed to CS provided some initial explanation to the dual role that Src may play under CS-induced oxidative stress. It was shown that the oxidative stress not only induced robust phosphorylation/activation of Src that subsequently activated nSMase2 to generate ceramide but also led the activated Src to strongly bind to the aberrantly CS-activated EGFR (58). Src mutants and inhibitors were used to analyze the role of Src in generating resistance to TKIs in EGFR-overexpressing NSCLC cells exposed to CS (57). The findings demonstrated that oxidative stress-activated Src is critical for the TKI-resistant phenotype observed in both the WT- and L858R MT EGFRexpressing cells during CS exposure, supporting the idea that targeting of Src during TKI treatment may overcome smoking/ oxidative stress-related aberrant EGFR activation and resistance to therapy in NSCLC (Figs. 5 and 6).

The unprecedented, dual function suggested for Src and its effect on ceramide generation thus provided a potential mechanistic link between smoking-induced lung injury and lung cancer. Such a role is corroborated in that the oxidative stress-induced active conformation of EGFR could be stabilized in ceramide-enriched cellular compartments (61), as discussed in Section VII.

\section{The Unexpected Role of Ceramide in Cell Proliferation and Tumorigenesis}

\section{A. Cell membrane ceramide-enriched signaling platform and stabilization of aberrantly activated EGFR}

Within the investigation on the mechanism linking redox signaling and lung epithelial cell proliferation, it was recently proposed that the oxidative stress-dependent activation of EGFR might be affected by changes in membrane structure/ fluidity (61). Consistently, it was shown in HAE cells that such EGFR activation is dependent on temperature and on membrane cholesterol/ceramide ratio (61). Moreover, the TKI AG1478 could not inhibit EGFR activation during oxidative stress in living cells, whereas it did inhibit it in a crude cell membrane fraction (broken cells), where the proper membrane structure was altered (61). Thus, it was suggested that the membrane lipid constituents may either induce or stabilize the oxidative stress-dependent active conformation of EGFR (58), a theory encouraged by several interesting observations involving the EGFR and the membrane lipid components.

\section{B. Membrane ordered lipid domains}

Recently, different groups showed that sphingolipids in cell membranes are not homogenously distributed but are instead compartmentalized into specific domains mediated by interactions between sphingolipids and cholesterol (238). Specifically, sphingolipids and cholesterol are strongly bound with each other because of complementary amphoteric interactions (122), resulting in high local concentration of sphingolipidsand cholesterol-enriched membrane domains known as membrane rafts or lipid rafts. It is believed that cholesterol and some of its precursors not only cooperate with sphingolipids in these membrane rafts but also stabilize the structure of rafts by packing open spaces between the massive sphingolipids (122, $201,226,238)$. It is generally accepted that membrane microdomains exist and facilitate the segregation of specific lipids and proteins, thereby initiating specific signaling events. However, the actual lipid composition and size of these membrane microdomains, or rafts, are still very debatable (162). The major problem is that the postulated diameters of these membrane rafts are in the nanometer order, and therefore, it is difficult to accurately visualize these distinct morphological structures. Thus, conclusions on their structure and functions were mainly drawn based on biochemical experiments that utilized detergent extraction of membranes 
followed by the isolation of the detergent-resistant membranes (DRMs) on sucrose density gradients. However, such methods inevitably induce various artifacts, confounding results, and interpretation. Moreover, it has been shown recently that there are DRMs that are "nonbuoyant" on sucrose density gradient. These DRMs were defined as "heavy" rafts, as opposed to the "light" or buoyant rafts. However, the specific lipid differences between "heavy" and "light" rafts have not been characterized, yet (162).

\section{Ceramide selectively displaces cholesterol from ordered lipid domains (rafts)}

Studies of the composition of artificial membranes demonstrated that the generation of ceramide by sphingomyelin hydrolysis can specifically displace cholesterol from the membrane rafts (145). Therefore, ceramide generation could change composition and structure of the rafts. Furthermore, it has been proposed that ceramide-enriched membrane domains are predisposed to fuse with each other, raising larger membrane domains, the "ceramide-enriched membrane platforms," whose diameters could reach the order of micrometers $(36,40$, $81,88,145,146,199)$. These ceramide platforms possess different biophysical properties compared to the "conventional" lipid raft (phospholipid- and cholesterol-enriched ones) and may control important cell functions, such as protein sorting and redistribution of membrane receptors, including the EGFR. Consistently, ceramide-enriched membrane platforms were shown to capture and cluster receptor proteins $(40,84,88)$. Therefore, since lipid rafts are thought to serve as signaling platforms for many membrane receptors, including the EGFR (94), changes in membrane structure and fluidity driven by ceramide generation from sphingomyelin breakdown are likely to significantly impact the phenotype and cell fate of airway epithelial cells.

\section{Ceramide/cholesterol ratio affects EGFR and Src}

Lambert et al. reported that the disruption of cholesterolenriched lipid rafts caused ligand-independent activation of EGFR (126). One potential explanation was provided by Wang et al. (216). This study suggested that a population of EGFRs is strongly associated with lipid rafts and their disruption by a cholesterol sequestering agent, such as $\mathrm{M} \beta \mathrm{CD}$, would cause the relocalization of EGFR in nonraft portions of the plasma membrane where it could be activated due to its release from raft-associated inhibiting factors (216).

At the same time, Filosto et al. found that no changes of total cholesterol levels could be observed in HAE cells exposed to oxidative stress (61). Furthermore, cholesterol uptake in the plasma membrane could inhibit such oxidative stress-induced activation of EGFR (61). Therefore, it was proposed that membrane ceramide generated during exposure to oxidative stress may displace cholesterol from the rafts, causing the EGFR to transfer to rigid ceramideenriched platforms, where an aberrant EGFR signaling occurs (61). Specifically, it was also shown that the aberrant binding between EGFR and active Src due to CS exposure was responsible for the TKI resistance in lung cancer patients (57). This interaction was not transient (i.e., in a rapid on/off equilibrium) but, instead, was stable. Thermodynamically, this could happen only if other supporting changes occur simultaneously. Therefore, it was suggested that alteration in the plasma membrane composition and fluidity, specifically the generation of ceramide from sphingomyelin by nSMase 2 activation observed during CS exposure, supports and stabilizes the abnormal active structures and interaction between EGFR and Src, as well as their aberrant functions.

\section{E. Ceramide, EGFR, and Src}

It was recently demonstrated that during oxidative stress, activated EGFR and activated Src not only strongly bind each other but also colocalize within ceramide-enriched membrane regions (61). Specifically, at early time points of oxidative stress exposure (15 min), active EGFR and elevated ceramide colocalize primarily in the plasma membrane of the cells, while at later time points (30 min), such colocalization is detected mainly in the perinucleus. Consistent with this last observation, it was previously shown that EGFR activated by oxidative stress, unlike the EGF-stimulated receptor, does not undergo clathrin-dependent internalization and subsequent lysosomal degradation. Instead, EGFR remains active and traffics via caveolae to the perinucleus because of strong binding to phosphorylated Cav-1 $(118,119)$, which is a known substrate of Src. Intriguingly, others have shown in vitro that ceramide generation at the plasma membrane promotes the recruitment of Cav-1 into caveolae $(125,230)$. Moreover, the oxidative stress-activated EGFR colocalized with the early endosome marker EEA-1 $(118,176)$ and the recycling endosome marker Rab-11 (unpublished observation). In summary, when airway epithelial cells are exposed to oxidative stress, ceramide generation could support the aberrant activation of EGFR and prompt the caveolindependent trafficking of EGFR to the cell perinucleus; this results in sustained EGFR signaling, which is a feature of lung cancer (119). However, whether the change in EGFR conformation under oxidative stress occurs as a result of simultaneous alterations in the membrane structure or happens independently and is only being stabilized by the simultaneous membrane changes requires additional studies.

\section{F. The link between ceramide and Src underlies their dual roles in apoptosis and proliferation}

Although it is believed that the generation of ceramide acts as a direct stimulus for apoptosis during cellular stress, it is similarly plausible that ceramide induces proliferation signaling and may thus promote tumorigenesis. Ceramide generation at the cell membrane triggers the formation of signaling platforms that can affect a number of membraneassociated proteins, including Src and EGFR (61), which in turn can initiate prosurvival/proliferation signaling cascades (Figs. 7 and 8).

Consistent with this dual role of ceramide, it has been recently shown in vitro that nSMase 2 function and subsequent ceramide generation under TNF- $\alpha$ - or oxidized lowdensity lipoprotein-induced cell stress can be mechanistically linked to both apoptosis initiation and cell proliferation (47). An additional recent publication claims that the loss of ceramide transfer protein (CERT) augments EGFR signaling in breast cancer via its regulation of a cellular pool of sphingomyelin (SM). Reduction of CERT expression led to increased ceramide and reduced SM levels, thereby enhancing tumorigenesis (94). Intriguingly, a recent article by Poirier et al. reports that nSMase 2 activity and ceramide level are 
FIG. 7. The proposed dual role of activated Src in the downstream ceramide accumulation, which in turn supports the CS/oxidative stress-dependent aberrant activation of EGFR. The CS-activated EGFR binds the Y416 phosphorylated Src and the Y14 phosphorylated Cav-1. It is not degraded and thus leads to tumorigenesis. To see this illustration in color, the reader is referred to the web version of this article at www.liebertpub.com/ ars

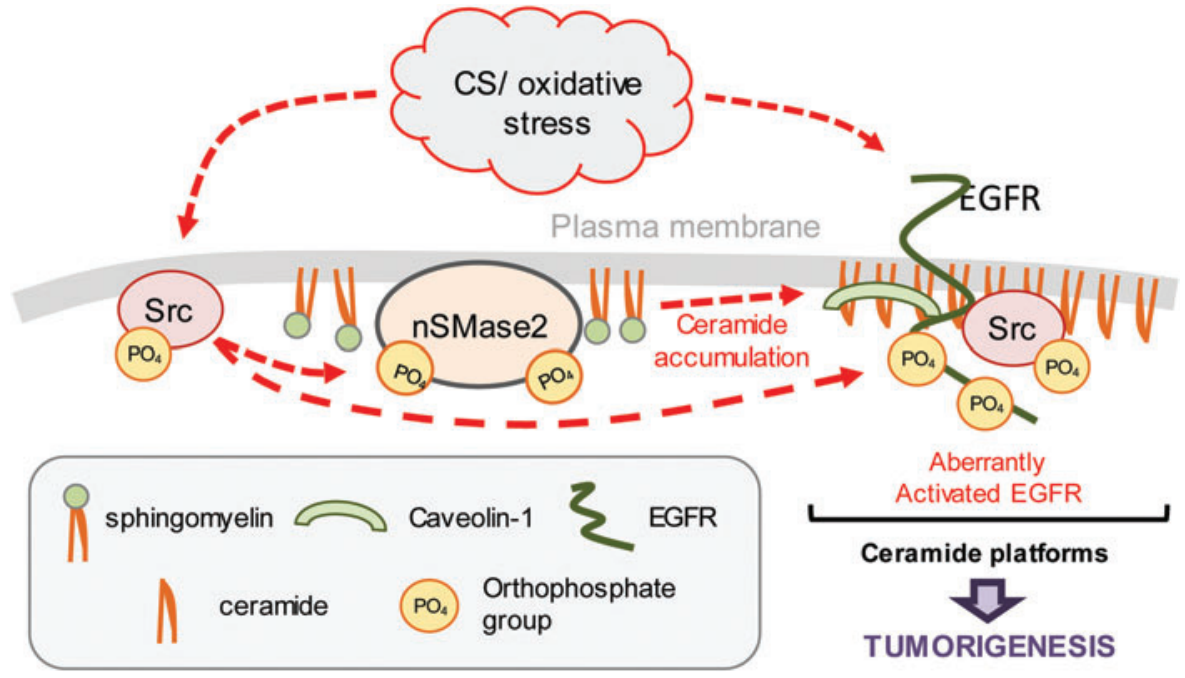

critical for lung development and function: systemic knockout of nSMase 2 catalytic function (fro/fro mice) caused reduced ceramide levels and abnormalities in the lungs, which appear to develop with congenital emphysema-like defects (enlarged alveoli and increased compliance of the respiratory system) (170); this was counterintuitive, based on the commonly accepted role of nSMase 2 function and ceramide upregulation in inducing lung injury and emphysema $(59,169)$. Therefore, it further proves that the role of ceramide in the lung as a mere detrimental lipid needs to be reevaluated. Notably, nSMase 2 and ceramide generation could be instrumental in the spreading of oncogenic proteins and microRNAs (miRNAs) via exosomal generation, as further described in section VIII.

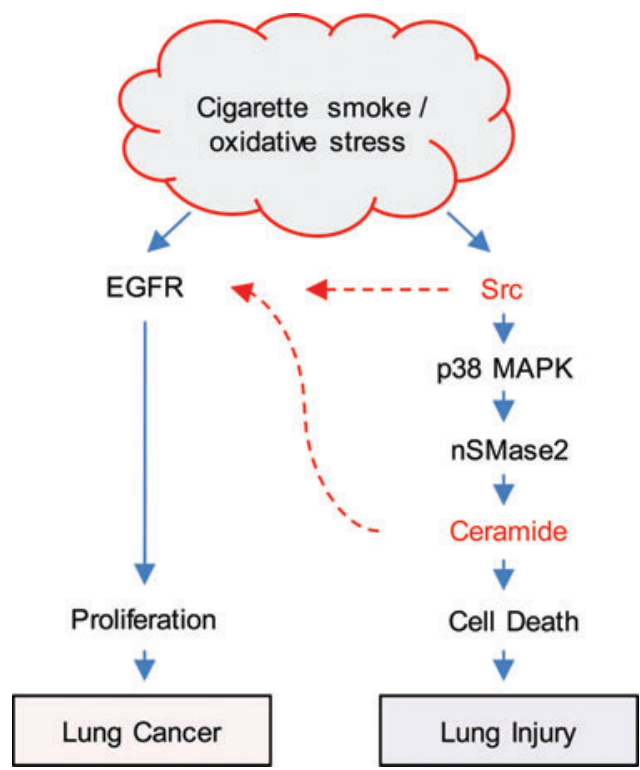

FIG. 8. General scheme of Src and the ceramide-generating machinery that have dual roles in lung injury and lung cancer. To see this illustration in color, the reader is referred to the web version of this article at www.liebertpub .com/ars

\section{Propagation of Oncogenes and miRNA via nSMase2-Dependent Ceramide Generation and Exosome Secretion}

Cell intercommunication has been conventionally described to occur via gradients of soluble molecules, which are recognized by cell-associated receptors. However, membrane nanovesicles coined exosomes have recently been identified as a new vehicle for cellular communication between cells that fuse with receiving cells in the neighboring area $(4,15,198)$. Exosomes can be viewed as "units" of information, containing a number of biologically active protein and RNA species, including oncogenic receptors and miRNAs, short noncoding RNAs that modulate gene expression $(121,135)$. Al-Nedawi et al. reported that EGFRvIII, a truncated and oncogenic form of EGFR, can be transferred via secretory exosomes from human brain glioma cells into neighboring cells lacking EGFRvIII (4). Moreover, a recent publication by Kosaka et al. demonstrated intercellular communication by miRNAs transfer (124). They showed that miRNAs could be secreted from donor cells in exosomes and thereby be incorporated in receiving cells while staying functional (124). Consistently, Pegtel et al. also found that miRNAs released from cells infected with Epstein-Barr virus were transferred to and affected recipient cells (166). Importantly, Kosaka et al. (124) further demonstrated that nSMase 2 function and ceramide generation control the formation and secretion of miRNA containing exosomes, underlining a novel fundamental path for the ceramide-generating machinery in regulating cell communication, gene expression, and cell fate.

At the present time, there are no reports on exosomal oncoprotein transfers in the lung. However, many studies, including studies on lung cancer, described the tumorigenic role of exosomes in that they can alter the gene expression of receiving cells by mediating transfer of functional miRNAs. Some miRNAs are deregulated in lung cancer and are associated with clinical outcomes. For example, low expression of let-7a miRNA and high expression of miR-155 miRNA were linked with poor clinical outcome (228). The let-7 miRNA has been widely reported to be differentially lower expressed in lung cancers, including CS-induced lung cancer (109); at the same time, let-7 miRNA can attenuate oxidant-induced injury 
through increasing the levels of HO1 (102), one of the key ubiquitous antioxidant enzymes. Thus, changes in miRNAs, including let-7 miRNA, could participate in the molecular linkage between injury and cancer development.

Notably, many miRNAs are overexpressed in lung cancer and can modulate cancerous cell growth via affecting EGFR function (136). In addition, miRNA-containing exosomes could be collected from the plasma of tumor patients, including lung cancer patients, thereby potentially serving as prognostic biomarkers $(5,23,149)$. Thus, ceramide-dependent secretion of exosomes can control the transfer of oncoproteins and onco-miRNAs between the subset of cell populations, contributing to tumorigenesis. Consistently, Kosaka et al. demonstrated in vivo (mice) that the nSMase2-dependent exosomal transfer of angiogenic miRNAs regulates cancer cell metastasis (123).

On the other hand, exosome release by nSMase2-dependent mechanism as well as exosome uptake in recipient cells has been recently associated with cytotoxic effects in NSCLC cells (74). This demonstrates that such a nanovesicle-mediated machinery can also have proapoptotic effects (Fig. 9). Therefore, whether cells engage in proliferation or apoptosis in response to exosome-dependent signaling will likely depend on the stimuli induced, as well as on processes of adaptation to stress.

\section{Updates on Novel Unresolved Complexities in the Ceramide-Generating Machinery}

Additional complexity of this underinvestigated field stems from recent studies showing that suppression or stimulation of tumor growth by ceramide could be observed and could be dependent on the length of the fatty acid chain of ceramide (93). For instance, as recently reviewed by Saddoughi and Ogretmen, C(16)-ceramide was implicated in cancer cell proliferation, whereas $\mathrm{C}(18)$-ceramide mediated cancer cell death (183). Moreover, this could lead to different subcellular localization and therefore to different downstream targets (203), all of which could be also cell-type specific.

In addition, several enzyme families are already known to be involved in ceramide generation (93). However, at the present time, very little is known on their regulation under various stress stimuli/conditions. Recent studies are demonstrating the critical role of ceramide in modulating cell proliferation as a metabolite within the greater sphingolipid machinery. This allows the conversion of what is once a proapoptotic sphingolipid to ones that have proliferative signaling properties $(78,183)$. For example, Mitra et al. investigated ceramide kinase and its critical role in converting ceramide to ceramide-1-phosphate (C1P), a sphingolipid metabolite demonstrated to have threshold-like effects on cell proliferation (150). In A549 lung adenocarcinoma cells, low levels of C1P drove cell proliferation, whereas high levels of $\mathrm{C} 1 \mathrm{P}$ led to apoptosis, possibly due to the conversion of C1P to ceramide (150).

At the same time, a recent publication by Petrache et al. presents that the de novo ceramide synthesis plays a critical role in maintaining the lung structure and function (in vitro and in vivo). Using a murine knockout model, it was shown that downregulation of ceramide synthase 2 resulted in a compensatory increase of ceramide synthase 5 activity. This caused the accumulation of ceramide species that harbor 16 carbon atoms in the fatty acid chain (C16-ceramide) and enlargement of lung parenchymal spaces (resembling emphy-

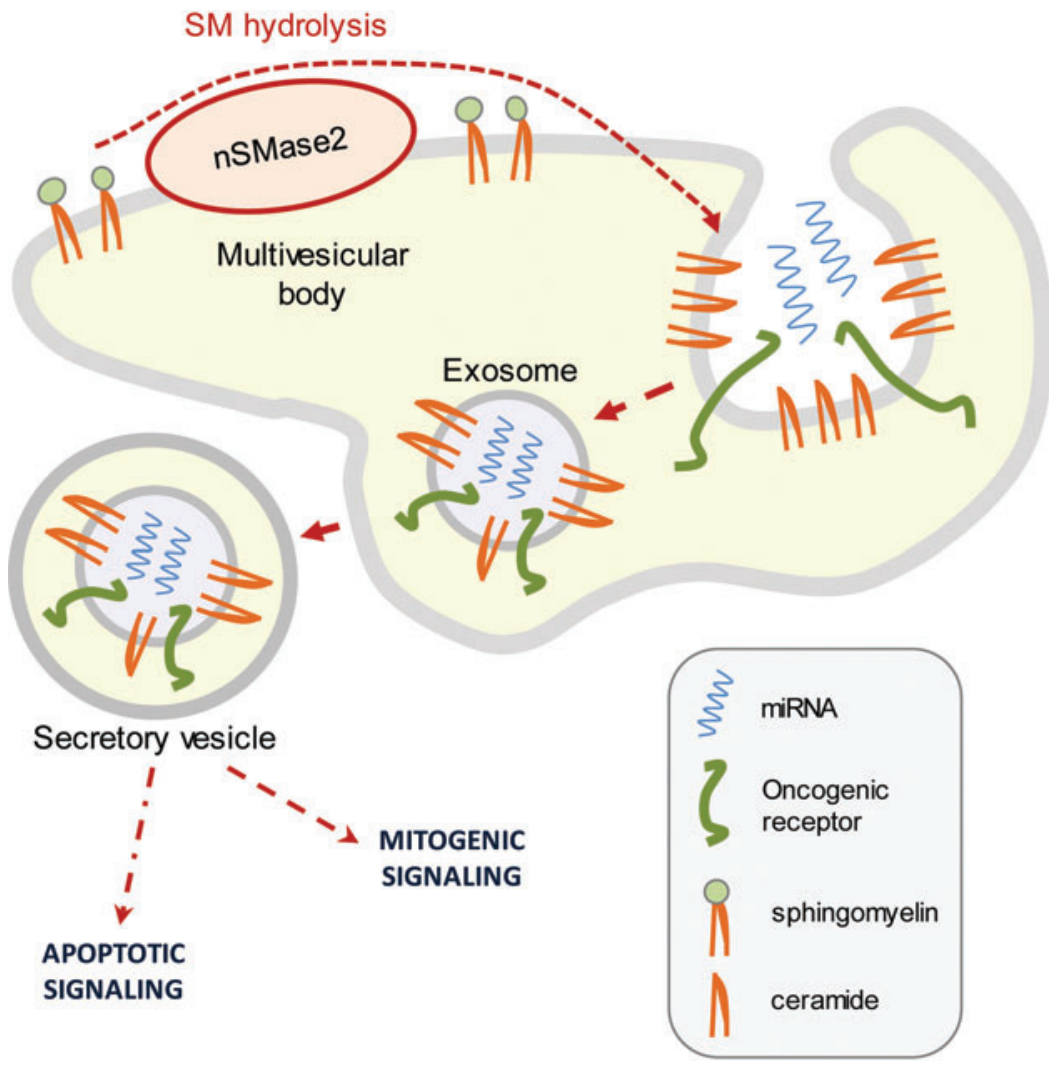

FIG. 9. Proposed model of nSMase2dependent exosomal formation and secretion. nSMase 2 is essential for the formation of secretory exosomes, underscoring the structural/functional role of ceramide in generating exosomes that may carry oncogenic receptors (such as the EGFR VIII) and/or miRNA. Therefore, exosomes may lead to both apoptosis and proliferation of recipient cells. miRNA, microRNAs. To see this illustration in color, the reader is referred to the web version of this article at www.liebertpub.com/ars 
sematous changes) (168). Another recent publication by Sultan et al. (203) presented in vitro that $\mathrm{H}_{2} \mathrm{O}_{2}$ could potentiate the de novo ceramide pathway by cotreatment of lung cancer cells with "short-chain" C6-ceramide, resulting in C16-ceramide accumulation and inhibition of the proto-oncogene c-Myc (myelocytomatosis viral oncogene homolog) (203).

Importantly, such examples include interesting cell- and tissue-fate observations tied to specific ceramide/sphingolipid species, indicating that we are only "scratching the surface of the iceberg" containing the puzzle of the ceramide-generating machinery.

\section{Therapeutic Perspectives}

Although specific inhibitors of nSMase 2 are still not available, a few options already exist in the drug market to target Src and p38 MAPK. In a phase II clinical trial, Laurie et al. suggested that saracatinib, an orally available inhibitor of SFKs, may benefit a subset of NSCLC patients, which is currently molecularly undetermined; thus, further use of saracatinib in populations preselected for target mutations and smoking status should be considered (129). For instance, saracatinib could be functional as a combinatory therapy with EGFR TKIs, erlotinib or gefinitib, in patients who are smokers or former smokers and harboring activating EGFR mutations. Conversely, a small phase II clinical trial presented by Johnson et al. found that dasatinib, an Src-specific inhibitor, has little-to-no efficacy in patients with EGFRmutant lung adenocarcinoma who acquired resistance to erlotinib and gefinitib; however, this trial included mostly never-smokers (113). To the best of our knowledge, no clinical trial has evaluated so far the use of SFK inhibitors in controlling COPD. On the other hand, p38 MAPK inhibition has recently been used in COPD patients with promising outcomes. For instance, Singh et al. found in a small cohort of randomized patients that SB-681323, a potent p38 MAPK inhibitor, strongly suppressed inflammation in COPD (197). Consistently, MacNee et al. presented that PH-797804 (another orally available p38 MAPK inhibitor) improved lung function parameters in a randomized cohort of 230 COPD patients (138). To date, the use of p38 MAPK inhibitors in lung cancer trials has not been assessed, although a potential role for p38 MAPK in lung tumorigenesis and resistance to therapy has been observed in vitro in $\operatorname{NSCLC~}(28,85)$.

In summary, despite the rising attention to the nexus between COPD and lung cancer, it is still important and necessary to additionally study the molecular pathways underlying both lung injury and lung cancer, which urge novel drug discovery and clinical trials.

\section{Concluding Remarks}

In this review, several years of studies investigating redox signaling are described. Specific signaling pathways that lead to cell death and to cell proliferation/tumorigenesis were demonstrated in lung airway epithelial cells exposed to CS. In search for common molecular pathways and targets in lung injury and lung cancer, ceramide, a lipid metabolite, was highlighted as a tentative target. This canonically proapoptotic sphingolipid, which already had been described to have a role in lung injury (59), was suggested to also have potential roles in promoting cell proliferation and lung tumorigenesis. To provide the specific context for such a dichotomous role of ceramide, the review focuses on CS-induced oxidative stress and its effects on the airway epithelium.

On one hand, ceramide is generated by the activation of the axis Src-p38 MAPK-nSMase2 during oxidative stress, eventually leading to apoptosis, which is the dominant pathway in lung injury/COPD. On the other hand, the same stimulus aberrantly activates the EGFR, leading to prolonged proliferative signaling as observed in NSCLC. Interestingly, recent studies provide evidence that these two CS-activated pathways may actually converge and interact. Specifically, it was recently found in lung epithelial cells exposed to CS/ oxidative stress that EGFR and Src are bound together and preferentially colocalize in ceramide-enriched regions of the plasma membrane, suggesting that nSMase2/ceramide may directly affect the aberrant EGFR/Src activation and mutual interaction, leading to enhanced proliferation/tumorigenic signaling (61).

Moreover, new findings show that CS-induced oxidative stress exposure induces resistance to EGFR-targeted (TKI) therapy, solely through post-translational molecular changes. These molecular alterations consist of an aberrant EGFR phosphorylation pattern accompanied by an aberrant conformation, which is supported by Src binding and activity $(57,58)$. Intriguingly, these structural anomalies of the oxidative stress-activated EGFR could be supported by the formation of ceramide-enriched microdomains generated in the plasma membrane of lung epithelial cells, which is dependent on Src and p38 MAPK function (29).

Due to the plethora of observations reported herein, the ceramide-generating machinery presents a novel array of target proteins, such as Src, p38 MAPK, and nSMase2, which may serve in mediating smoking-induced lung injury and lung cancer.

\section{Acknowledgments}

This work was supported by grants from National Institutes of Health (HL-66189 to T.G.) and from the TobaccoRelated Disease Research Program (TRDRP) (17RT-0131 and 22RT-0090 to T.G. and 20FT-0087 to S.F.).

\section{References}

1. The definition of emphysema. Report of a National Heart, Lung, and Blood Institute, Division of Lung Diseases workshop. Am Rev Respir Dis 132: 182-185, 1985.

2. Cigarette smoking and health. American Thoracic Society. Am J Respir Crit Care Med 153: 861-865, 1996.

3. Adcock IM, Caramori G, and Barnes PJ. Chronic obstructive pulmonary disease and lung cancer: new molecular insights. Respiration 81: 265-284, 2011.

4. Al-Nedawi K, Meehan B, Micallef J, Lhotak V, May L, Guha A, and Rak J. Intercellular transfer of the oncogenic receptor EGFRvIII by microvesicles derived from tumour cells. Nat Cell Biol 10: 619-624, 2008.

5. Al-Nedawi K, Meehan B, and Rak J. Microvesicles: messengers and mediators of tumor progression. Cell Cycle 8: 2014-2018, 2009.

6. Alberg AJ and Samet JM. Epidemiology of lung cancer. Chest 123: 21S-49S, 2003.

7. Anthonisen NR, Skeans MA, Wise RA, Manfreda J, Kanner RE, and Connett JE. The effects of a smoking 
cessation intervention on 14.5-year mortality: a randomized clinical trial. Ann Intern Med 142: 233-239, 2005.

8. Aoshiba K, Yokohori N, and Nagai A. Alveolar wall apoptosis causes lung destruction and emphysematous changes. Am J Respir Cell Mol Biol 28: 555-562, 2003.

9. Artaud-Macari E, Goven D, Brayer S, Hamimi A, Besnard V, Marchal-Somme J, Ali ZE, Crestani B, Kerdine-Romer S, Boutten A, and Bonay M. Nuclear factor erythroid 2related factor 2 nuclear translocation induces myofibroblastic dedifferentiation in idiopathic pulmonary fibrosis. Antioxid Redox Signal 18: 66-79, 2013.

10. Bae YS, Kang SW, Seo MS, Baines IC, Tekle E, Chock $\mathrm{PB}$, and Rhee SG. Epidermal growth factor (EGF)induced generation of hydrogen peroxide. Role in EGF receptor-mediated tyrosine phosphorylation. J Biol Chem 272: 217-221, 1997.

11. Bao J, Gur G, and Yarden Y. Src promotes destruction of c-Cbl: implications for oncogenic synergy between Src and growth factor receptors. Proc Natl Acad Sci U S A 100: 2438-2443, 2003.

12. Barsky SH, Roth MD, Kleerup EC, Simmons M, and Tashkin DP. Histopathologic and molecular alterations in bronchial epithelium in habitual smokers of marijuana, cocaine, and/or tobacco. J Natl Cancer Inst 90: 11981205, 1998.

13. Berghmans T, Meert AP, Mascaux C, Paesmans M, Lafitte JJ, and Sculier JP. Citation indexes do not reflect methodological quality in lung cancer randomised trials. Ann Oncol 14: 715-721, 2003.

14. Bhalla DK, Hirata F, Rishi AK, and Gairola CG. Cigarette smoke, inflammation, and lung injury: a mechanistic perspective. J Toxicol Environ Health B Crit Rev 12: 4564, 2009.

15. Bhowmick NA, Neilson EG, and Moses HL. Stromal fibroblasts in cancer initiation and progression. Nature 432: 332-337, 2004.

16. Biscardi JS, Maa MC, Tice DA, Cox ME, Leu TH, and Parsons SJ. c-Src-mediated phosphorylation of the epidermal growth factor receptor on Tyr845 and Tyr1101 is associated with modulation of receptor function. $J$ Biol Chem 274: 8335-8343, 1999.

17. Bublil EM, Pines G, Patel G, Fruhwirth G, Ng T, and Yarden Y. Kinase-mediated quasi-dimers of EGFR. FASEB J 24: 4744-4755, 2010.

18. Burdick AD, Davis JW, 2nd, Liu KJ, Hudson LG, Shi H, Monske ML, and Burchiel SW. Benzo(a)pyrene quinones increase cell proliferation, generate reactive oxygen species, and transactivate the epidermal growth factor receptor in breast epithelial cells. Cancer Res 63: 78257833, 2003.

19. Cao H, Sanguinetti AR, and Mastick CC. Oxidative stress activates both Src-kinases and their negative regulator Csk and induces phosphorylation of two targeting proteins for Csk: caveolin-1 and paxillin. Exp Cell Res 294: 159-171, 2004.

20. Castillo SS, Levy M, Thaikoottathil JV, and Goldkorn T. Reactive nitrogen and oxygen species activate different sphingomyelinases to induce apoptosis in airway epithelial cells. Exp Cell Res 313: 2680-2686, 2007.

21. Castillo SS, Levy M, Wang C, Thaikoottathil JV, Khan E, and Goldkorn T. Nitric oxide-enhanced caspase-3 and acidic sphingomyelinase interaction: a novel mechanism by which airway epithelial cells escape ceramide-induced apoptosis. Exp Cell Res 313: 816-823, 2007.
22. Chan $\mathrm{C}$ and Goldkorn T. Ceramide path in human lung cell death. Am J Respir Cell Mol Biol 22: 460-468, 2000.

23. Chen X, Ba Y, Ma L, Cai X, Yin Y, Wang K, Guo J, Zhang Y, Chen J, Guo X, Li Q, Li X, Wang W, Wang J, Jiang X, Xiang Y, Xu C, Zheng P, Zhang J, Li R, Zhang $H$, Shang $X$, Gong T, Ning G, Zen K, and Zhang CY. Characterization of microRNAs in serum: a novel class of biomarkers for diagnosis of cancer and other diseases. Cell Res 18: 997-1006, 2008.

24. Cho HY and Kleeberger SR. Nrf2 protects against airway disorders. Toxicol Appl Pharmacol 244: 43-56, 2010.

25. Chung BM, Dimri M, George M, Reddi AL, Chen G, Band $\mathrm{V}$, and Band $\mathrm{H}$. The role of cooperativity with Src in oncogenic transformation mediated by non-small cell lung cancer-associated EGF receptor mutants. Oncogene 28: 1821-1832, 2009.

26. Chung BM, Raja SM, Clubb RJ, Tu C, George M, Band $\mathrm{V}$, and Band $\mathrm{H}$. Aberrant trafficking of NSCLC-associated EGFR mutants through the endocytic recycling pathway promotes interaction with Src. BMC Cell Biol 10: 84, 2009.

27. Chung I, Akita R, Vandlen R, Toomre D, Schlessinger J, and Mellman I. Spatial control of EGF receptor activation by reversible dimerization on living cells. Nature 464: 783-787, 2010.

28. Chung LY, Tang SJ, Sun GH, Chou TY, Yeh TS, Yu SL, and Sun KH. Galectin-1 promotes lung cancer progression and chemoresistance by upregulating p38 MAPK, ERK, and cyclooxygenase-2. Clin Cancer Res 18: 40374047, 2012.

29. Chung S, Filosto S, and Goldkorn T. Src activates Neutral Sphingomyelinase 2 (nSMase2) during cigarette-smoke induced oxidative stress via PKC $\delta$ and p38 MAPK in human lung epithelial cells. ATS Conference (Philadelphia), 2013.

30. Church DF and Pryor WA. Free-radical chemistry of cigarette smoke and its toxicological implications. Environ Health Perspect 64: 111-126, 1985.

31. Churg A, Dai J, Tai H, Xie C, and Wright JL. Tumor necrosis factor-alpha is central to acute cigarette smokeinduced inflammation and connective tissue breakdown. Am J Respir Crit Care Med 166: 849-854, 2002.

32. Churg A, Wang RD, Tai H, Wang X, Xie C, and Wright JL. Tumor necrosis factor-alpha drives $70 \%$ of cigarette smoke-induced emphysema in the mouse. Am J Respir Crit Care Med 170: 492-498, 2004.

33. Cinq-Frais C, Coatrieux C, Grazide MH, Hannun YA, Negre-Salvayre A, Salvayre R, and Auge N. A signaling cascade mediated by ceramide, src and PDGFRbeta coordinates the activation of the redox-sensitive neutral sphingomyelinase-2 and sphingosine kinase-1. Biochim Biophys Acta 1831: 1344-1356, 2013.

34. Clarke CJ, Guthrie JM, and Hannun YA. Regulation of neutral sphingomyelinase-2 (nSMase2) by tumor necrosis factor-alpha involves protein kinase C-delta in lung epithelial cells. Mol Pharmacol 74: 1022-1032, 2008.

35. Clarke CJ, Truong TG, and Hannun YA. Role for neutral sphingomyelinase- 2 in tumor necrosis factor alpha-stimulated expression of vascular cell adhesion molecule-1 (VCAM) and intercellular adhesion molecule-1 (ICAM) in lung epithelial cells: p38 MAPK is an upstream regulator of nSMase2. J Biol Chem 282: 1384-1396, 2007.

36. Contreras FX, Villar AV, Alonso A, Kolesnick RN, and Goni FM. Sphingomyelinase activity causes transbilayer 
lipid translocation in model and cell membranes. $J$ Biol Chem 278: 37169-37174, 2003.

37. Cooper WA, Lam DC, O'Toole SA, and Minna JD. Molecular biology of lung cancer. J Thorac Dis 5: S479S490, 2013.

38. Couet J, Li S, Okamoto T, Ikezu T, and Lisanti MP. Identification of peptide and protein ligands for the caveolinscaffolding domain. Implications for the interaction of caveolin with caveolae-associated proteins. J Biol Chem 272: 6525-6533, 1997.

39. Couet J, Sargiacomo M, and Lisanti MP. Interaction of a receptor tyrosine kinase, EGF-R, with caveolins. Caveolin binding negatively regulates tyrosine and serine/threonine kinase activities. J Biol Chem 272: 30429-30438, 1997.

40. Cremesti A, Paris F, Grassme H, Holler N, Tschopp J, Fuks Z, Gulbins E, and Kolesnick R. Ceramide enables fas to cap and kill. J Biol Chem 276: 23954-23961, 2001.

41. D’Angelo SP, Pietanza MC, Johnson ML, Riely GJ, Miller VA, Sima CS, Zakowski MF, Rusch VW, Ladanyi M, and Kris MG. Incidence of EGFR exon 19 deletions and L858R in tumor specimens from men and cigarette smokers with lung adenocarcinomas. J Clin Oncol 29: 2066-2070, 2011.

42. Dawson JP, Berger MB, Lin CC, Schlessinger J, Lemmon MA, and Ferguson KM. Epidermal growth factor receptor dimerization and activation require ligand-induced conformational changes in the dimer interface. Mol Cell Biol 25: 7734-7742, 2005.

43. de Torres JP, Bastarrika G, Wisnivesky JP, Alcaide AB, Campo A, Seijo LM, Pueyo JC, Villanueva A, Lozano MD, Montes U, Montuenga L, and Zulueta JJ. Assessing the relationship between lung cancer risk and emphysema detected on low-dose CT of the chest. Chest 132: 19321938, 2007.

44. de Torres JP, Marin JM, Casanova C, Cote C, Carrizo S, Cordoba-Lanus E, Baz-Davila R, Zulueta JJ, AguirreJaime A, Saetta M, Cosio MG, and Celli BR. Lung cancer in patients with chronic obstructive pulmonary diseaseincidence and predicting factors. Am J Respir Crit Care Med 184: 913-919, 2011.

45. Demedts IK, Demoor T, Bracke KR, Joos GF, and Brusselle GG. Role of apoptosis in the pathogenesis of COPD and pulmonary emphysema. Respir Res 7: 53, 2006.

46. Denu JM and Tanner KG. Specific and reversible inactivation of protein tyrosine phosphatases by hydrogen peroxide: evidence for a sulfenic acid intermediate and implications for redox regulation. Biochemistry 37: 56335642, 1998.

47. Devillard R, Galvani S, Thiers JC, Guenet JL, Hannun Y, Bielawski J, Negre-Salvayre A, Salvayre R, and Auge N. Stress-induced sphingolipid signaling: role of type-2 neutral sphingomyelinase in murine cell apoptosis and proliferation. PLoS One 5: e9826, 2010.

48. Ding L, Getz G, Wheeler DA, Mardis ER, McLellan MD, Cibulskis K, Sougnez C, Greulich H, Muzny DM, Morgan MB, Fulton L, Fulton RS, Zhang Q, Wendl MC, Lawrence MS, Larson DE, Chen K, Dooling DJ, Sabo A, Hawes AC, Shen H, Jhangiani SN, Lewis LR, Hall O, Zhu Y, Mathew T, Ren Y, Yao J, Scherer SE, Clerc K, Metcalf GA, Ng B, Milosavljevic A, Gonzalez-Garay ML, Osborne JR, Meyer R, Shi X, Tang Y, Koboldt DC, Lin L, Abbott R, Miner TL, Pohl C, Fewell G, Haipek C, Schmidt H, Dunford-Shore BH, Kraja A, Crosby SD, Sawyer CS, Vickery T, Sander S, Robinson J, Winckler W, Baldwin J,
Chirieac LR, Dutt A, Fennell T, Hanna M, Johnson BE, Onofrio RC, Thomas RK, Tonon G, Weir BA, Zhao X, Ziaugra L, Zody MC, Giordano T, Orringer MB, Roth JA, Spitz MR, Wistuba, II, Ozenberger B, Good PJ, Chang AC, Beer DG, Watson MA, Ladanyi M, Broderick S, Yoshizawa A, Travis WD, Pao W, Province MA, Weinstock GM, Varmus HE, Gabriel SB, Lander ES, Gibbs RA, Meyerson M, and Wilson RK. Somatic mutations affect key pathways in lung adenocarcinoma. Nature 455: 1069-1075, 2008.

49. Dittmann K, Mayer C, Kehlbach R, and Rodemann HP. Radiation-induced caveolin-1 associated EGFR internalization is linked with nuclear EGFR transport and activation of DNA-PK. Mol Cancer 7: 69, 2008.

50. Don Ryoo $\mathrm{H}$ and Bergmann A. The role of apoptosisinduced proliferation for regeneration and cancer. Cold Spring Harbor Perspect Biol 4: a008797, 2012.

51. Duan L, Miura Y, Dimri M, Majumder B, Dodge IL, Reddi AL, Ghosh A, Fernandes N, Zhou P, MullaneRobinson K, Rao N, Donoghue S, Rogers RA, Bowtell D, Naramura M, Gu H, Band V, and Band H. Cbl-mediated ubiquitinylation is required for lysosomal sorting of epidermal growth factor receptor but is dispensable for endocytosis. J Biol Chem 278: 28950-28960, 2003.

52. Dvorak HF. Tumors: wounds that do not heal. Similarities between tumor stroma generation and wound healing. $N$ Engl J Med 315: 1650-1659, 1986.

53. Elias J, Kang M, Crothers K, Homer R, and Lee C. State of the art. Mechanistic heterogeneity in chronic COPD: insights from transgenic mice. Proc Am Thorac Soc 3: 494-498, 2006.

54. Elias JA and Lee CG. Lipid let loose in pulmonary emphysema. Nat Med 11: 471-472, 2005.

55. Ellis AG, Doherty MM, Walker F, Weinstock J, Nerrie M, Vitali A, Murphy R, Johns TG, Scott AM, Levitzki A, McLachlan G, Webster LK, Burgess AW, and Nice EC. Preclinical analysis of the analinoquinazoline AG1478, a specific small molecule inhibitor of EGF receptor tyrosine kinase. Biochem Pharmacol 71: 14221434, 2006.

56. Filosto S, Ashfaq M, Chung S, Fry W, and Goldkorn T. Neutral sphingomyelinase 2 activity and protein stability are modulated by phosphorylation of five conserved serines. J Biol Chem 287: 514-522, 2012.

57. Filosto S, Baston DS, Chung S, Becker CR, and Goldkorn T. Src mediates cigarette smoke-induced resistance to tyrosine kinase inhibitors in NSCLC cells. Mol Cancer Ther 12: 1579-1590, 2013.

58. Filosto S, Becker CR, and Goldkorn T. Cigarette smoke induces aberrant EGF receptor activation that mediates lung cancer development and resistance to tyrosine kinase inhibitors. Mol Cancer Ther 11: 795-804, 2012.

59. Filosto S, Castillo S, Danielson A, Franzi L, Khan E, Kenyon N, Last J, Pinkerton K, Tuder R, and Goldkorn T. Neutral sphingomyelinase 2: a novel target in cigarette smoke-induced apoptosis and lung injury. Am J Respir Cell Mol Biol 44: 350-360, 2011.

60. Filosto S, Fry W, Knowlton AA, and Goldkorn T. Neutral sphingomyelinase 2 (nSMase2) is a phosphoprotein regulated by calcineurin (PP2B). J Biol Chem 285: 1021310222, 2010.

61. Filosto S, Khan E, Tognon E, Becker C, Ashfaq M, Ravid $\mathrm{T}$, and Goldkorn T. EGF receptor exposed to oxidative stress acquires abnormal phosphorylation and aberrant 
activated conformation that impairs canonical dimerization. PLoS One 6: e23240, 2011.

62. Foschino Barbaro MP, Carpagnano GE, Spanevello A, Cagnazzo MG, and Barnes PJ. Inflammation, oxidative stress and systemic effects in mild chronic obstructive pulmonary disease. Int J Immunopathol Pharmacol 20: 753-763, 2007.

63. Fra AM, Williamson E, Simons K, and Parton RG. De novo formation of caveolae in lymphocytes by expression of VIP21-caveolin. Proc Natl Acad Sci U S A 92: 86558659, 1995.

64. Franklin WA, Veve R, Hirsch FR, Helfrich BA, and Bunn PA, Jr. Epidermal growth factor receptor family in lung cancer and premalignancy. Semin Oncol 29: 3-14, 2002.

65. Fuchs-Tarlovsky V. Role of antioxidants in cancer therapy. Nutrition 29: 15-21, 2012.

66. Fujikawa K, de Aos Scherpenseel I, Jain SK, Presman E, and Christensen RA, Varticovski L. Role of PI 3-kinase in angiopoietin-1-mediated migration and attachment- dependent survival of endothelial cells [published erratum appears in Exp Cell Res 2000 Feb 25;255(1):133]. Exp Cell Res 253: 663-672, 1999.

67. Fukazawa T, Miyake S, Band V, and Band H. Tyrosine phosphorylation of $\mathrm{Cbl}$ upon epidermal growth factor (EGF) stimulation and its association with EGF receptor and downstream signaling proteins. J Biol Chem 271: 14554-14559, 1996.

68. Galbiati F, Razani B, and Lisanti MP. Emerging themes in lipid rafts and caveolae. Cell 106: 403-411, 2001.

69. Gamou S and Shimizu N. Hydrogen peroxide preferentially enhances the tyrosine phosphorylation of epidermal growth factor receptor. FEBS Lett 357: 161-164, 1995.

70. Ganesan S, Unger BL, Comstock AT, Angel KA, Mancuso P, Martinez FJ, and Sajjan US. Aberrantly activated EGFR contributes to enhanced IL- 8 expression in COPD airways epithelial cells via regulation of nuclear FoxO3A. Thorax 68: 131-141, 2013.

71. Garrett TP, McKern NM, Lou M, Elleman TC, Adams TE, Lovrecz GO, Zhu HJ, Walker F, Frenkel MJ, Hoyne PA, Jorissen RN, Nice EC, Burgess AW, and Ward CW. Crystal structure of a truncated epidermal growth factor receptor extracellular domain bound to transforming growth factor alpha. Cell 110: 763-773, 2002.

72. Geraghty P, Hardigan A, and Foronjy RF. Cigarette smoke activates the proto-oncogene $\mathrm{c}-\mathrm{Src}$ to promote airway inflammation and lung tissue destruction. Am J Respir Cell Mol Biol 50: 559-570, 2013.

73. Giaccone G and Zucali PA. Src as a potential therapeutic target in non-small-cell lung cancer. Ann Oncol 19: 12191223, 2008.

74. Gills JJ, Zhang C, Abu-Asab MS, Castillo SS, Marceau C, LoPiccolo J, Kozikowski AP, Tsokos M, Goldkorn T, and Dennis PA. Ceramide mediates nanovesicle shedding and cell death in response to phosphatidylinositol ether lipid analogs and perifosine. Cell Death Dis 3: e340, 2012.

75. Giordano RJ, Lahdenranta J, Zhen L, Chukwueke U, Petrache I, Langley RR, Fidler IJ, Pasqualini R, Tuder $\mathrm{RM}$, and Arap W. Targeted induction of lung endothelial cell apoptosis causes emphysema-like changes in the mouse. J Biol Chem 283: 29447-29460, 2008.

76. Goldkorn T, Balaban N, Matsukuma K, Last J, Chan C, and Chavez C. EGF-Receptor phosphorylation and signaling are targeted by $\mathrm{H}_{2} \mathrm{O}_{2}$ redox stress. Am J Respir Cell Mol Biol 19: 786-798, 1998.
77. Goldkorn T, Balaban N, Shannon M, Chea V, Matsukuma $\mathrm{K}$, Gilchrist D, Wang H, and Chan C. H2O2 acts on cellular membranes to generate ceramide signaling and initiate apoptosis in tracheobronchial epithelial cells. J Cell Sci 111: 3209-3220, 1998.

78. Goldkorn T, Chung S, and Filosto S. Lung cancer and lung injury: the dual role of ceramide. Handb Exp Pharmacol 216: 93-113, 2013.

79. Goldkorn $\mathrm{T}$ and Filosto S. Lung injury and cancer: mechanistic insights into ceramide and EGFR signaling under cigarette smoke. Am J Respir Cell Mol Biol 43: 259-268, 2010.

80. Goldkorn T, Ravid T, and Khan EM. Life and death decisions: ceramide generation and EGF receptor trafficking are modulated by oxidative stress. Antioxid Redox Signal 7: 119-128, 2005.

81. Goni FM and Alonso A. Effects of ceramide and other simple sphingolipids on membrane lateral structure. Biochim Biophys Acta 1788: 169-177, 2009.

82. Goven D, Boutten A, Lecon-Malas V, Boczkowski J, and Bonay M. Prolonged cigarette smoke exposure decreases heme oxygenase-1 and alters Nrf2 and Bach1 expression in human macrophages: roles of the MAP kinases ERK(1/2) and JNK. FEBS Lett 583: 3508-3518, 2009.

83. Goven D, Boutten A, Lecon-Malas V, Marchal-Somme J, Amara N, Crestani B, Fournier M, Leseche G, Soler P, Boczkowski J, and Bonay M. Altered Nrf2/Keap1-Bach1 equilibrium in pulmonary emphysema. Thorax 63: 916924, 2008.

84. Grassme H, Jekle A, Riehle A, Schwarz H, Berger J, Sandhoff K, Kolesnick R, and Gulbins E. CD95 signaling via ceramide-rich membrane rafts. J Biol Chem 276: 20589-20596, 2001.

85. Greenberg AK, Basu S, Hu J, Yie TA, Tchou-Wong KM, Rom WN, and Lee TC. Selective p38 activation in human non-small cell lung cancer. Am J Respir Cell Mol Biol 26: 558-564, 2002.

86. Greulich H. The genomics of lung adenocarcinoma: opportunities for targeted therapies. Genes Cancer 1: 12001210, 2010.

87. Gridelli C, Maione P, Bareschino MA, Schettino C, Sacco PC, Ambrosio R, Barbato V, Falanga M, and Rossi A. Erlotinib in the treatment of non-small cell lung cancer: current status and future developments. Anticancer Res 30: 1301-1310, 2010.

88. Gulbins E and Kolesnick R. Raft ceramide in molecular medicine. Oncogene 22: 7070-7077, 2003.

89. Halliwell B. Oxidative stress and cancer: have we moved forward? Biochem J 401: 1-11, 2007.

90. Halliwell B and Gutteridge JM. Role of free radicals and catalytic metal ions in human disease: an overview. Methods Enzymol 186: 1-85, 1990.

91. Halliwell B and Gutteridge JMC. Free Radicals in Biology and Medicine. New York: Oxford University Press, 2007.

92. Hannun YA and Obeid LM. The ceramide-centric universe of lipid-mediated cell regulation: stress encounters of the lipid kind. J Biol Chem 277: 25847-25850, 2002.

93. Hannun YA and Obeid LM. Many ceramides. J Biol Chem 286: 27855-27862, 2011.

94. Heering J, Weis N, Holeiter M, Neugart F, Staebler A, Fehm TN, Bischoff A, Schiller J, Duss S, Schmid S, Korte T, Herrmann A, and Olayioye MA. Loss of the ceramide 
transfer protein augments EGF receptor signaling in breast cancer. Cancer Res 72: 2855-2866, 2012.

95. Heneberg P. Lifting the fog of scientometric research artifacts: on the scientometric analysis of environmental tobacco smoke research. J Am Soc Inf Sci Technol 62: 334-344, 2013.

96. Henson PM, Vandivier RW, and Douglas IS. Cell death, remodeling, and repair in chronic obstructive pulmonary disease? Proc Am Thorac Soc 3: 713-717, 2006.

97. Herold S, Mayer K, and Lohmeyer J. Acute lung injury: how macrophages orchestrate resolution of inflammation and tissue repair. Front Immunol 2: 65, 2011.

98. Hirota K, Murata M, Itoh T, Yodoi J, and Fukuda K. Redox-sensitive transactivation of epidermal growth factor receptor by tumor necrosis factor confers the NF-kappa B activation. J Biol Chem 276: 25953-25958, 2001.

99. Hirsch FR, Bunn PA, Jr., Johnson DH, Giaccone G, and Rosell R. Lung cancer. Introduction. Lung Cancer 41 Suppl 1: S1, 2003.

100. Hirsch FR, Scagliotti GV, Langer CJ, Varella-Garcia M, and Franklin WA. Epidermal growth factor family of receptors in preneoplasia and lung cancer: perspectives for targeted therapies. Lung Cancer 41 Suppl 1: S29-S42, 2003.

101. Hoidal JR. Reactive oxygen species and cell signaling. Am J Respir Cell Mol Biol 25: 661-663, 2001.

102. Hou W, Tian Q, Steuerwald NM, Schrum LW, and Bonkovsky HL. The let-7 microRNA enhances heme oxygenase-1 by suppressing Bach1 and attenuates oxidant injury in human hepatocytes. Biochim Biophys Acta 1819: 11131122, 2012.

103. Houghton AM. Mechanistic links between COPD and lung cancer. Nat Rev Cancer 13: 233-245, 2013.

104. Huang F, Kirkpatrick D, Jiang X, Gygi S, and Sorkin A. Differential regulation of EGF receptor internalization and degradation by multiubiquitination within the kinase domain. Mol Cell 21: 737-748, 2006.

105. Huang RP, Peng A, Golard A, Hossain MZ, Huang R, Liu $\mathrm{YG}$, and Boynton AL. Hydrogen peroxide promotes transformation of rat liver non-neoplastic epithelial cells through activation of epidermal growth factor receptor. Mol Carcinog 30: 209-217, 2001.

106. Hynes NE and Lane HA. ERBB receptors and cancer: the complexity of targeted inhibitors. Nat Rev Cancer 5: 341354, 2005.

107. Ikezu T, Trapp BD, Song KS, Schlegel A, Lisanti MP, and Okamoto T. Caveolae, plasma membrane microdomains for alpha-secretase-mediated processing of the amyloid precursor protein. J Biol Chem 273: 1048510495, 1998.

108. Ise N, Omi K, Miwa K, Honda H, Higashiyama S, and Goishi K. Novel monoclonal antibodies recognizing the active conformation of epidermal growth factor receptor. Biochem Biophys Res Commun 394: 685-690, 2010.

109. Izzotti A, Calin GA, Arrigo P, Steele VE, Croce CM, and De Flora S. Downregulation of microRNA expression in the lungs of rats exposed to cigarette smoke. FASEB J 23: 806-812, 2009.

110. Jemal A, Murray T, Samuels A, Ghafoor A, Ward E, and Thun MJ. Cancer statistics, 2003. CA Cancer J Clin 53: 526, 2003.

111. Jiang X, Huang F, Marusyk A, and Sorkin A. Grb2 regulates internalization of EGF receptors through clathrincoated pits. Mol Biol Cell 14: 858-870, 2003.
112. Jiang $X$ and Sorkin A. Epidermal growth factor receptor internalization through clathrin-coated pits requires $\mathrm{Cbl}$ RING finger and proline-rich domains but not receptor polyubiquitylation. Traffic 4: 529-543, 2003.

113. Johnson ML, Riely GJ, Rizvi NA, Azzoli CG, Kris MG, Sima CS, Ginsberg MS, Pao W, and Miller VA. Phase II trial of dasatinib for patients with acquired resistance to treatment with the epidermal growth factor receptor tyrosine kinase inhibitors erlotinib or gefitinib. J Thorac Oncol 6: 1128-1131, 2011.

114. Kamocki K, Van Demark M, Fisher A, Rush NI, Presson RG, Jr., Hubbard W, Berdyshev EV, Adamsky S, Feinstein E, Gandjeva A, Tuder RM, and Petrache I. RTP801 is required for ceramide-induced cell-specific death in the murine lung. Am J Respir Cell Mol Biol 48: 87-93, 2013.

115. Kang HR, Cho SJ, Lee CG, Homer RJ, and Elias JA. TGF-betal stimulates pulmonary fibrosis and inflammation via a Bax-dependent, bid-activated pathway that involves matrix metalloproteinase-12. J Biol Chem 282: 7723-7732, 2007.

116. Kasahara Y, Tuder R, Cool C, Lynch D, Flores S, and Voelkel NF. Endothelial cell death and decreased expression of vascular endothelial growth factor and vascular endothelial growth factor receptor 2 in emphysema. Am J Respir Crit Care Med 163: 737-744, 2007.

117. Kasahara Y, Tuder RM, Taraseviciene-Stewart L, Le Cras TD, Abman S, Hirth PK, Waltenberger J, and Voelkel NF. Inhibition of VEGF receptors causes lung cell apoptosis and emphysema. J Clin Invest 106: 1311-1319, 2000.

118. Khan E, Heidinger J, Levy M, Lisanti M, Ravid T, and Goldkorn T. EGF receptor exposed to oxidative stress undergoes Src- and caveolin-1-dependent perinuclear trafficking. J Biol Chem 281: 14486-14493, 2006.

119. Khan EM, Lanir R, Danielson AR, and Goldkorn T. EGF receptor exposed to cigarette smoke is aberrantly activated and undergoes perinuclear trafficking. FASEB J 22: 910917, 2008.

120. Kim H, Chan R, Dankort DL, Zuo D, Najoukas M, Park $\mathrm{M}$, and Muller WJ. The c-Src tyrosine kinase associates with the catalytic domain of ErbB-2: implications for ErbB-2 mediated signaling and transformation. Oncogene 24: 7599-7607, 2005.

121. Kim VN, Han J, and Siomi MC. Biogenesis of small RNAs in animals. Nat Rev Mol Cell Biol 10: 126-139, 2009.

122. Kolesnick RN, Goni FM, and Alonso A. Compartmentalization of ceramide signaling: physical foundations and biological effects. J Cell Physiol 184: 285-300, 2000.

123. Kosaka N, Iguchi H, Hagiwara K, Yoshioka Y, Takeshita F, and Ochiya T. Neutral sphingomyelinase 2 (nSMase2)dependent exosomal transfer of angiogenic microRNAs regulate cancer cell metastasis. J Biol Chem 288: 1084910859, 2013.

124. Kosaka N, Iguchi H, Yoshioka Y, Takeshita F, Matsuki Y, and Ochiya T. Secretory mechanisms and intercellular transfer of microRNAs in living cells. $J$ Biol Chem 285: 17442-17452, 2010.

125. Kuebler WM, Yang Y, Samapati R, and Uhlig S. Vascular barrier regulation by PAF, ceramide, caveolae, and NOan intricate signaling network with discrepant effects in the pulmonary and systemic vasculature. Cell Physiol Biochem 26: 29-40, 2010.

126. Lambert S, Vind-Kezunovic D, Karvinen S, and Gniadecki R. Ligand-independent activation of the EGFR by 
lipid raft disruption. J Invest Dermatol 126: 954-962, 2006.

127. This reference has been deleted.

128. Laude AJ and Prior IA. Plasma membrane microdomains: organization, function and trafficking. Mol Membr Biol 21: 193-205, 2004.

129. Laurie SA, Goss GD, Shepherd FA, Neil Reaume M, Nicholas G, Philip L, Wang L, Schwock J, Hirsh V, Oza A, Tsao MS, Wright JJ, and Leighl NB. A phase II trial of saracatinib, an inhibitor of src kinases, in previouslytreated advanced non-small-cell lung cancer: the princess margaret hospital phase II consortium. Clin Lung Cancer 15: 52-57, 2013.

130. Lavrentiadou SN, Chan C, Ravid T, Tsaba A, van der Vliet A, Rasooly R, and Goldkorn T. Ceramide-mediated apoptosis in lung epithelial cells is regulated by GSH. Am J Respir Cell Mol Biol 25: 676-684, 2001.

131. Lee SR, Kwon KS, Kim SR, and Rhee SG. Reversible inactivation of protein-tyrosine phosphatase 1B in A431 cells stimulated with epidermal growth factor. $J$ Biol Chem 273: 15366-15372, 1998.

132. Levkowitz G, Waterman H, Ettenberg SA, Katz M, Tsygankov AY, Alroy I, Lavi S, Iwai K, Reiss Y, Ciechanover A, Lipkowitz S, and Yarden Y. Ubiquitin ligase activity and tyrosine phosphorylation underlie suppression of growth factor signaling by c-Cbl/Sli-1. Mol Cell 4: 1029-1040, 1999.

133. Levy M, Castillo SS, and Goldkorn T. nSMase 2 activation and trafficking are modulated by oxidative stress to induce apoptosis. Biochem Biophys Res Commun 344: 900-905, 2006.

134. Levy M, Khan E, Careaga M, and Goldkorn T. Neutral sphingomyelinase 2 is activated by cigarette smoke to augment ceramide-induced apoptosis in lung cell death. Am J Physiol Lung Cell Mol Physiol 297: 125-133, 2009.

135. Liu X, Sempere LF, Galimberti F, Freemantle SJ, Black C, Dragnev $\mathrm{KH}$, Ma Y, Fiering S, Memoli V, Li H, DiRenzo J, Korc M, Cole CN, Bak M, Kauppinen S, and Dmitrovsky E. Uncovering growth-suppressive MicroRNAs in lung cancer. Clin Cancer Res 15: 1177-1183, 2009.

136. Liu X, Sempere LF, Ouyang H, Memoli VA, Andrew AS, Luo Y, Demidenko E, Korc M, Shi W, Preis M, Dragnev KH, Li H, Direnzo J, Bak M, Freemantle SJ, Kauppinen S, and Dmitrovsky E. MicroRNA-31 functions as an oncogenic microRNA in mouse and human lung cancer cells by repressing specific tumor suppressors. J Clin Invest 120: 1298-1309, 2010.

137. Maa MC, Leu TH, McCarley DJ, Schatzman RC, and Parsons SJ. Potentiation of epidermal growth factor receptormediated oncogenesis by c-Src: implications for the etiology of multiple human cancers. Proc Natl Acad Sci U S A 92: 6981-6985, 1995.

138. MacNee W, Allan RJ, Jones I, De Salvo MC, and Tan LF. Efficacy and safety of the oral p38 inhibitor PH-797804 in chronic obstructive pulmonary disease: a randomised clinical trial. Thorax 68: 738-745, 2013.

139. Mahadeva R and Lomas DA. Genetics and respiratory disease. 2. Alpha 1-antitrypsin deficiency, cirrhosis and emphysema. Thorax 53: 501-505, 1998.

140. Malhotra D, Thimmulappa R, Navas-Acien A, Sandford A, Elliott M, Singh A, Chen L, Zhuang X, Hogg J, Pare P, Tuder RM, and Biswal S. Decline in NRF2-regulated antioxidants in chronic obstructive pulmonary disease lungs due to loss of its positive regulator, DJ-1. Am J Respir Crit Care Med 178: 592-604, 2008.

141. Marcotte R, Zhou L, Kim H, Roskelly CD, and Muller WJ. c-Src associates with ErbB2 through an interaction between catalytic domains and confers enhanced transforming potential. Mol Cell Biol 29: 5858-5871, 2009.

142. Marmor MD and Yarden Y. Role of protein ubiquitylation in regulating endocytosis of receptor tyrosine kinases. Oncogene 23: 2057-2070, 2004.

143. Mates JM, Segura JA, Alonso FJ, and Marquez J. Oxidative stress in apoptosis and cancer: an update. Arch Toxicol 86: 1649-1665, 2012.

144. Medina-Ramon M, Zanobetti A, and Schwartz J. The effect of ozone and PM10 on hospital admissions for pneumonia and chronic obstructive pulmonary disease: a national multicity study. Am J Epidemiol 163: 579-588, 2006.

145. Megha and London E. Ceramide selectively displaces cholesterol from ordered lipid domains (rafts): implications for lipid raft structure and function. $J$ Biol Chem 279: 9997-10004, 2004.

146. Megha, Sawatzki P, Kolter T, Bittman R, and London E. Effect of ceramide $\mathrm{N}$-acyl chain and polar headgroup structure on the properties of ordered lipid domains (lipid rafts). Biochim Biophys Acta 1768: 2205-2212, 2007.

147. Melgert BN, Timens W, Kerstjens HA, Geerlings M, Schouten JP, Postma DS, and Hylkema MN. Effects of 4 months of smoking in mice with ovalbumin-induced airway inflammation. Clin Exp Allergy 37: 1798-1808, 2007.

148. Mio T, Romberger DJ, Thompson AB, Robbins RA, Heires A, and Rennard SI. Cigarette smoke induces interleukin-8 release from human bronchial epithelial cells. Am J Respir Crit Care Med 155: 1770-1776, 1997.

149. Mitchell PS, Parkin RK, Kroh EM, Fritz BR, Wyman SK, Pogosova-Agadjanyan EL, Peterson A, Noteboom J, O'Briant KC, Allen A, Lin DW, Urban N, Drescher CW, Knudsen BS, Stirewalt DL, Gentleman R, Vessella RL, Nelson PS, Martin DB, and Tewari M. Circulating microRNAs as stable blood-based markers for cancer detection. Proc Natl Acad Sci U S A 105: 10513-10518, 2008.

150. Mitra P, Maceyka M, Payne SG, Lamour N, Milstien S, Chalfant CE, and Spiegel S. Ceramide kinase regulates growth and survival of A549 human lung adenocarcinoma cells. FEBS Lett 581: 735-740, 2007.

151. Mosesson Y, Shtiegman K, Katz M, Zwang Y, Vereb G, Szollosi J, and Yarden Y. Endocytsosis of receptor tyrosine kinases is driven by mono-, not poly-ubiquitylation. $J$ Biol Chem 278: 21323-21326, 2003.

152. Mouded M, Egea EE, Brown MJ, Hanlon SM, Houghton AM, Tsai LW, Ingenito EP, and Shapiro SD. Epithelial cell apoptosis causes acute lung injury masquerading as emphysema. Am J Respir Cell Mol Biol 41: 407-414, 2009.

153. Mountzios G, Fouret P, and Soria JC. Mechanisms of disease: signal transduction in lung carcinogenesis-a comparison of smokers and never-smokers. Nat Clin Pract Oncol 5: 610-618, 2008.

154. Mudway IS and Kelly FJ. Ozone and the lung: a sensitive issue. Mol Aspects Med 21: 1-48, 2000.

155. Murphy SL. Deaths: final data for 1998. Natl Vital Stat Rep 48: 1-105, 2000. 
156. Nabi IR and Le PU. Caveolae/raft-dependent endocytosis. J Cell Biol 161: 673-677, 2003.

157. Nakayama T, Kodama M, and Nagata C. Generation of hydrogen proxide and superoxide anion radical from cigarette smoke. Gann 75: 95-98, 1984.

158. Nikolova-Karakashian M, Karakashian A, and Rutkute K. Role of neutral sphingomyelinases in aging and inflammation. Subcell Biochem 49: 469-486, 2008.

159. O’Donnell RA, Richter A, Ward J, Angco G, Mehta A, Rousseau K, Swallow DM, Holgate ST, Djukanovic R, Davies DE, and Wilson SJ. Expression of ErbB receptors and mucins in the airways of long term current smokers. Thorax 59: 1032-1040, 2004.

160. Ogiso H, Ishitani R, Nureki O, Fukai S, Yamanaka M, Kim JH, Saito K, Sakamoto A, Inoue M, Shirouzu M, and Yokoyama S. Crystal structure of the complex of human epidermal growth factor and receptor extracellular domains. Cell 110: 775-787, 2002.

161. Oh P, McIntosh DP, and Schnitzer JE. Dynamin at the neck of caveolae mediates their budding to form transport vesicles by GTP-driven fission from the plasma membrane of endothelium. J Cell Biol 141: 101-114, 1998.

162. Otahal P, Angelisova P, Hrdinka M, Brdicka T, Novak P, Drbal K, and Horejsi V. A new type of membrane raft-like microdomains and their possible involvement in TCR signaling. J Immunol 184: 3689-3696, 2010.

163. Paez JG, Janne PA, Lee JC, Tracy S, Greulich H, Gabriel S, Herman P, Kaye FJ, Lindeman N, Boggon TJ, Naoki K, Sasaki H, Fujii Y, Eck MJ, Sellers WR, Johnson BE, and Meyerson M. EGFR mutations in lung cancer: correlation with clinical response to gefitinib therapy. Science 304: 1497-1500, 2004.

164. Park JW, Ryter SW, and Choi AM. Functional significance of apoptosis in chronic obstructive pulmonary disease. COPD 4: 347-353, 2007.

165. Parkin DM, Bray F, Ferlay J, and Pisani P. Global cancer statistics, 2002. CA Cancer J Clin 55: 74-108, 2005.

166. Pegtel DM, Cosmopoulos K, Thorley-Lawson DA, van Eijndhoven MA, Hopmans ES, Lindenberg JL, de Gruijl TD, Wurdinger T, and Middeldorp JM. Functional delivery of viral miRNAs via exosomes. Proc Natl Acad Sci U S A 107: 6328-6333, 2010.

167. Pelkmans L, Burli T, Zerial M, and Helenius A. Caveolinstabilized membrane domains as multifunctional transport and sorting devices in endocytic membrane traffic. Cell 118: 767-780, 2004.

168. Petrache I, Kamocki K, Poirier C, Pewzner-Jung Y, Laviad EL, Schweitzer KS, Van Demark M, Justice MJ, Hubbard WC, and Futerman AH. Ceramide synthases expression and role of ceramide synthase- 2 in the lung: insight from human lung cells and mouse models. PLoS One 8: e62968, 2013.

169. Petrache I, Natarajan V, Zhen L, Medler TR, Richter AT, Cho C, Hubbard WC, Berdyshev EV, and Tuder RM. Ceramide upregulation causes pulmonary cell apoptosis and emphysemalike disease in mice. Nat Med 11: 491-498, 2005.

170. Poirier C, Berdyshev EV, Dimitropoulou C, Bogatcheva $\mathrm{NV}$, Biddinger PW, and Verin AD. Neutral sphingomyelinase 2 deficiency is associated with lung anomalies similar to emphysema. Mamm Genome 23: 758-763, 2012.

171. Polosa R, Prosperini G, Leir SH, Holgate ST, Lackie PM, and Davies DE. Expression of c-erbB receptors and ligands in human bronchial mucosa. Am J Respir Cell Mol Biol 20: 914-923, 1999.
172. Quest AF, Leyton L, and Parraga M. Caveolins, caveolae, and lipid rafts in cellular transport, signaling, and disease. Biochem Cell Biol 82: 129-144, 2004.

173. Rahman I. Oxidative stress in pathogenesis of chronic obstructive pulmonary disease: cellular and molecular mechanisms. Cell Biochem Biophys 43: 167-188, 2005.

174. Rahman I. Regulation of GSH in inflammation and chronic lung diseases. Mutat Res 579: 58-80, 2005.

175. Rahman I. The role of oxidative stress in the pathogenesis of COPD: implications for therapy. Treat Respir Med 4: 175-200, 2005.

176. Ravid T, Heidinger J, Gee P, Khan E, and Goldkorn T. c-Cbl-mediated ubiquitinylation is required for EGF receptor exit from the early endosomes. J Biol Chem 279: 37153-37162, 2004.

177. Ravid T, Sweeney C, Gee P, Carraway KRK, and Goldkorn T. EGF receptor activation under oxidative stress fails to promote $\mathrm{c}-\mathrm{Cbl}$ mediated down regulation. $J$ Biol Chem 12: 12, 2002.

178. Ravid T, Tsaba A, Gee P, Rasooly R, Medina EA, and Goldkorn T. Ceramide accumulation precedes caspase-3 activation during apoptosis of A549 human lung adeno. cells. Am J Physiol Lung Cell Mol Physiol 284: L1082L1092, 2003.

179. Rennard SI, Togo S, and Holz O. Cigarette smoke inhibits alveolar repair: a mechanism for the development of emphysema. Proc Am Thorac Soc 3: 703-708, 2006.

180. Reunanen N, Westermarck J, Hakkinen L, Holmstrom TH, Elo I, Eriksson JE, and Kahari VM. Enhancement of fibroblast collagenase (matrix metalloproteinase-1) gene expression by ceramide is mediated by extracellular signal-regulated and stress-activated protein kinase pathways. J Biol Chem 273: 5137-5145, 1998.

181. Reynolds AR, Tischer C, Verveer PJ, Rocks O, and Bastiaens PI. EGFR activation coupled to inhibition of tyrosine phosphatases causes lateral signal propagation. Nat Cell Biol 5: 447-453, 2003.

182. Rutkute K, Karakashian AA, Giltiay NV, Dobierzewska A, and Nikolova-Karakashian MN. Aging in rat causes hepatic hyperresposiveness to IL-1beta which is mediated by nSMase2. Hepatology 46: 1166-1176, 2007.

183. Saddoughi SA and Ogretmen B. Diverse functions of ceramide in cancer cell death and proliferation. $A d v$ Cancer Res 117: 37-58, 2013.

184. Samara KD, Margaritopoulos G, Wells AU, Siafakas NM, and Antoniou KM. Smoking and pulmonary fibrosis: novel insights. Pulm Med 2011: 461439, 2011.

185. Sanguinetti AR, Cao H, and Corley Mastick C. Fyn is required for oxidative- and hyperosmotic-stress-induced tyrosine phosphorylation of caveolin-1. Biochem J 376: 159-168, 2003.

186. Sanguinetti AR and Mastick CC. c-Abl is required for oxidative stress-induced phosphorylation of caveolin-1 on tyrosine 14. Cell Signal 15: 289-298, 2003.

187. Schettino C, Bareschino MA, Sacco PC, Maione P, Rossi A, Casaluce F, Sgambato A, and Gridelli C. New molecular targets in the treatment of NSCLC. Curr Pharm Des 19: 5333-5343, 2013.

188. Schlessinger J. Cell signaling by receptor tyrosine kinases. Cell 103: 211-225, 2000.

189. Schlessinger J. Ligand-induced, receptor-mediated dimerization and activation of EGF receptor. Cell 110: 669$672,2002$. 
190. Schweitzer KS, Hatoum H, Brown MB, Gupta M, Justice MJ, Beteck B, Van Demark M, Gu Y, Presson RG, Jr., Hubbard WC, and Petrache I. Mechanisms of lung endothelial barrier disruption induced by cigarette smoke: role of oxidative stress and ceramides. Am J Physiol Lung Cell Mol Physiol 301: L836-L846, 2011.

191. Segura-Valdez L, Pardo A, Gaxiola M, Uhal BD, Becerril C, and Selman M. Upregulation of gelatinases A and B, collagenases 1 and 2, and increased parenchymal cell death in COPD. Chest 117: 684-694, 2000.

192. Sen $C$ and Packer L. Antioxidant and redox regulation of gene transcription. FASEB J 10: 709-720, 1996.

193. Shajahan AN, Timblin BK, Sandoval R, Tiruppathi C, Malik $\mathrm{AB}$, and Minshall RD. Role of Src-induced dynamin-2 phosphorylation in caveolae-mediated endocytosis in endothelial cells. J Biol Chem 279: 20392-20400, 2004.

194. Shajahan AN, Tiruppathi C, Smrcka AV, Malik AB, and Minshall RD. Gbetagamma activation of Src induces caveolae-mediated endocytosis in endothelial cells. $J$ Biol Chem 279: 48055-48062, 2004.

195. Sharma SV, Bell DW, Settleman J, and Haber DA. Epidermal growth factor receptor mutations in lung cancer. Nat Rev Cancer 7: 169-181, 2007.

196. Shtiegman K, Kochupurakkal BS, Zwang Y, Pines G, Starr A, Vexler A, Citri A, Katz M, Lavi S, Ben-Basat Y, Benjamin S, Corso S, Gan J, Yosef RB, Giordano S, and Yarden Y. Defective ubiquitinylation of EGFR mutants of lung cancer confers prolonged signaling. Oncogene 26: 6968-6978, 2007.

197. Singh D, Smyth L, Borrill Z, Sweeney L, and Tal-Singer R. A randomized, placebo-controlled study of the effects of the p38 MAPK inhibitor SB-681323 on blood biomarkers of inflammation in COPD patients. $J$ Clin Pharmacol 50: 94-100, 2010.

198. Skog J, Wurdinger T, van Rijn S, Meijer DH, Gainche L, Sena-Esteves M, Curry WT, Jr., Carter BS, Krichevsky AM, and Breakefield XO. Glioblastoma microvesicles transport RNA and proteins that promote tumour growth and provide diagnostic biomarkers. Nat Cell Biol 10: 1470-1476, 2008.

199. Sot J, Ibarguren M, Busto JV, Montes LR, Goni FM, and Alonso A. Cholesterol displacement by ceramide in sphingomyelin-containing liquid-ordered domains, and generation of gel regions in giant lipidic vesicles. FEBS Lett 582: 3230-3236, 2008.

200. Spurzem JR and Rennard SI. Pathogenesis of COPD. Semin Respir Crit Care Med 26: 142-153, 2005.

201. Stancevic B and Kolesnick R. Ceramide-rich platforms in transmembrane signaling. FEBS Lett 584: 1728-1740, 2010.

202. Sudol M. From Rous sarcoma virus to plasminogen activator, src oncogene and cancer management. Oncogene 30: 3003-3010, 2011.

203. Sultan I, Senkal CE, Ponnusamy S, Bielawski J, Szulc Z, Bielawska A, Hannun YA, and Ogretmen B. Regulation of the sphingosine-recycling pathway for ceramide generation by oxidative stress, and its role in controlling cMyc/Max function. Biochem J 393: 513-521, 2006.

204. Sung SY, Hsieh CL, Wu D, Chung LW, and Johnstone PA. Tumor microenvironment promotes cancer progression, metastasis, and therapeutic resistance. Curr Probl Cancer 31: 36-100, 2007.

205. Sznajder JI, Fraiman A, Hall JB, Sanders W, Schmidt G, Crawford G, Nahum A, Factor P, and Wood LD. In- creased $\mathrm{H}_{2} \mathrm{O}_{2}$ in the expired breath of patients with acute hypoxemic respiratory failure. Chest 96: 606-612, 1989.

206. Takeyama K, Jung B, Shim JJ, Burgel PR, Dao-Pick T, Ueki IF, Protin U, Kroschel P, and Nadel JA. Activation of epidermal growth factor receptors is responsible for mucin synthesis induced by cigarette smoke. Am J Physiol Lung Cell Mol Physiol 280: L165-L172, 2001.

207. Tetley TD. Macrophages and the pathogenesis of COPD. Chest 121: 156S-159S, 2002.

208. Tice DA, Biscardi JS, Nickles AL, and Parsons SJ. Mechanism of biological synergy between cellular Src and epidermal growth factor receptor. Proc Natl Acad Sci U S A 96: 1415-1420, 1999.

209. Tuder RM, Petrache I, Elias JA, and Voelkel NF, Henson PM. Apoptosis and emphysema: the missing link. Am J Respir Cell Mol Biol 28: 551-554, 2003.

210. Tuder RM, Yoshida T, Fijalkowka I, Biswal S, and Petrache I. Role of lung maintenance program in the heterogeneity of lung destruction in emphysema. Proc Am Thorac Soc 3: 673-679, 2006.

211. Turner MC, Chen Y, Krewski D, Calle EE, and Thun MJ. Chronic obstructive pulmonary disease is associated with lung cancer mortality in a prospective study of never smokers. Am J Respir Crit Care Med 176: 285-290, 2007.

212. Uhlig S and Gulbins E. Sphingolipids in the lungs. Am J Respir Crit Care Med 178: 1100-1114, 2008.

213. Urbe S, Sachse M, Row PE, Preisinger C, Barr FA, Strous G, Klumperman J, and Clague MJ. The UIM domain of Hrs couples receptor sorting to vesicle formation. J Cell Sci 116: 4169-4179, 2003.

214. Ushio-Fukai M, Griendling KK, Becker PL, Hilenski L, Halleran S, and Alexander RW. Epidermal growth factor receptor transactivation by angiotensin II requires reactive oxygen species in vascular smooth muscle cells. Arterioscler Thromb Vasc Biol 21: 489-495, 2001.

215. Van Winkle LS, Isaac JM, and Plopper CG. Distribution of epidermal growth factor receptor and ligands during bronchiolar epithelial repair from naphthalene-induced Clara cell injury in the mouse. Am J Pathol 151: 443-459, 1997.

216. Wang XQ, Yan Q, Sun P, Liu JW, Go L, McDaniel SM, and Paller AS. Suppression of epidermal growth factor receptor signaling by protein kinase $\mathrm{C}$-alpha activation requires CD82, caveolin-1, and ganglioside. Cancer Res 67: 9986-9995, 2007.

217. Watanabe S, Tanaka J, Ota T, Kondo R, Tanaka H, Kagamu H, Ichikawa K, Koshio J, Baba J, Miyabayashi T, Narita I, and Yoshizawa H. Clinical responses to EGFRtyrosine kinase inhibitor retreatment in non-small cell lung cancer patients who benefited from prior effective gefitinib therapy: a retrospective analysis. BMC Cancer 11: 1, 2011.

218. Waterman H, Katz M, Rubin C, Shtiegman K, Lavi S, Elson A, Jovin T, and Yarden Y. A mutant EGF-receptor defective in ubiquitylation and endocytosis unveils a role for Grb2 in negative signaling. EMBO J 21: 303-313, 2002.

219. Waterman H and Yarden Y. Molecular mechanisms underlying endocytosis and sorting of ErbB receptor tyrosine kinases. FEBS Lett 490: 142-152, 2001.

220. Weir BA, Woo MS, Getz G, Perner S, Ding L, Beroukhim R, Lin WM, Province MA, Kraja A, Johnson LA, Shah K, Sato M, Thomas RK, Barletta JA, Borecki IB, Broderick S, Chang AC, Chiang DY, Chirieac LR, Cho J, Fujii Y, 
Gazdar AF, Giordano T, Greulich H, Hanna M, Johnson BE, Kris MG, Lash A, Lin L, Lindeman N, Mardis ER, McPherson JD, Minna JD, Morgan MB, Nadel M, Orringer $\mathrm{MB}$, Osborne JR, Ozenberger B, Ramos AH, Robinson J, Roth JA, Rusch V, Sasaki H, Shepherd F, Sougnez C, Spitz MR, Tsao MS, Twomey D, Verhaak RG, Weinstock GM, Wheeler DA, Winckler W, Yoshizawa A, Yu S, Zakowski MF, Zhang Q, Beer DG, Wistuba, II, Watson MA, Garraway LA, Ladanyi M, Travis WD, Pao W, Rubin MA, Gabriel SB, Gibbs RA, Varmus HE, Wilson RK, Lander ES, and Meyerson M. Characterizing the cancer genome in lung adenocarcinoma. Nature 450: 893-898, 2007.

221. Wiley HS. Trafficking of the ErbB receptors and its influence on signaling. Exp Cell Res 284: 78-88, 2003.

222. Williams MD and Chance B. Spontaneous chemiluminescence of human breath. Spectrum, lifetime, temporal distribution, and correlation with peroxide. J Biol Chem 258: 3628-3631, 1983.

223. Woodruff PG. Novel outcomes and end points: biomarkers in chronic obstructive pulmonary disease clinical trials. Proc Am Thorac Soc 8: 350-355, 2011.

224. Wu BX, Clarke CJ, and Hannun YA. Mammalian neutral sphingomyelinases: regulation and roles in cell signaling responses. Neuromolecular Med 12: 320-330, 2010.

225. Wu JY, Wu SG, Yang CH, Chang YL, Chang YC, Hsu YC, Shih JY, and Yang PC. Comparison of gefitinib and erlotinib in advanced NSCLC and the effect of EGFR mutations. Lung Cancer 72: 205-212, 2011.

226. Xu X, Bittman R, Duportail G, Heissler D, Vilcheze C, and London E. Effect of the structure of natural sterols and sphingolipids on the formation of ordered sphingoli$\mathrm{pid} / \mathrm{sterol}$ domains (rafts). Comparison of cholesterol to plant, fungal, and disease-associated sterols and comparison of sphingomyelin, cerebrosides, and ceramide. J Biol Chem 276: 33540-33546, 2001

227. Xu Y, Tan LJ, Grachtchouk V, Voorhees JJ, and Fisher GJ. Receptor-type protein-tyrosine phosphatase-kappa regulates epidermal growth factor receptor function. J Biol Chem 280: 42694-42700, 2005.

228. Yanaihara N, Caplen N, Bowman E, Seike M, Kumamoto K, Yi M, Stephens RM, Okamoto A, Yokota J, Tanaka T, Calin GA, Liu CG, Croce CM, and Harris CC. Unique microRNA molecular profiles in lung cancer diagnosis and prognosis. Cancer Cell 9: 189-198, 2006.

229. Yang CH. EGFR tyrosine kinase inhibitors for the treatment of NSCLC in East Asia: present and future. Lung Cancer 60 Suppl 2: S23-S30, 2008.

230. Yang Y, Yin J, Baumgartner W, Samapati R, Solymosi EA, Reppien E, Kuebler WM, and Uhlig S. Plateletactivating factor reduces endothelial nitric oxide production: role of acid sphingomyelinase. Eur Respir J 36: 417-427, 2010.

231. Yarden Y. The EGFR family and its ligands in human cancer. Signalling mechanisms and therapeutic opportunities. Eur J Cancer 37 Suppl 4: S3-S8, 2001.

232. Yarden $Y$ and Sliwkowski MX. Untangling the ErbB signalling network. Nat Rev Mol Cell Biol 2: 127-137, 2001.

233. Yatabe Y. EGFR mutations and the terminal respiratory unit. Cancer Metastasis Rev 29: 23-36, 2010.

234. Yokouchi M, Kondo T, Houghton A, Bartkiewicz M, Horne WC, Zhang H, Yoshimura A, and Baron R. Ligandinduced ubiquitination of the epidermal growth factor receptor involves the interaction of the c-Cbl RING finger and UbcH7. J Biol Chem 274: 31707-31712, 1999.

235. Yoshida $T$ and Tuder RM. Pathobiology of cigarette smoke-induced chronic obstructive pulmonary disease. Physiol Rev 87: 1047-1082, 2007.

236. Zhang J, Kalyankrishna S, Wislez M, Thilaganathan N, Saigal B, Wei W, Ma L, Wistuba, II, Johnson FM, and Kurie JM. SRC-family kinases are activated in non-small cell lung cancer and promote the survival of epidermal growth factor receptor-dependent cell lines. Am J Pathol 170: 366-376, 2007.

237. Zhang X, Gureasko J, Shen K, Cole PA, and Kuriyan J. An allosteric mechanism for activation of the kinase domain of epidermal growth factor receptor. Cell 125: $1137-$ 1149, 2006.

238. Zhang Y, Li X, Becker KA, and Gulbins E. Ceramideenriched membrane domains - structure and function. Biochim Biophys Acta 1788: 178-183, 2009.

Address correspondence to: Dr. Tzipora Goldkorn Center for Comparative Respiratory Biology and Medicine Genome and Biomedical Sciences Facility University of California, Davis-School of Medicine 451 E. Health Sciences Dr.

Davis, CA 95616

E-mail: ttgoldkorn@ucdavis.edu

Date of first submission to ARS Central, September 7, 2013; date of final revised submission, March 16, 2014; date of acceptance, March 29, 2014.

\begin{tabular}{|c|}
\hline 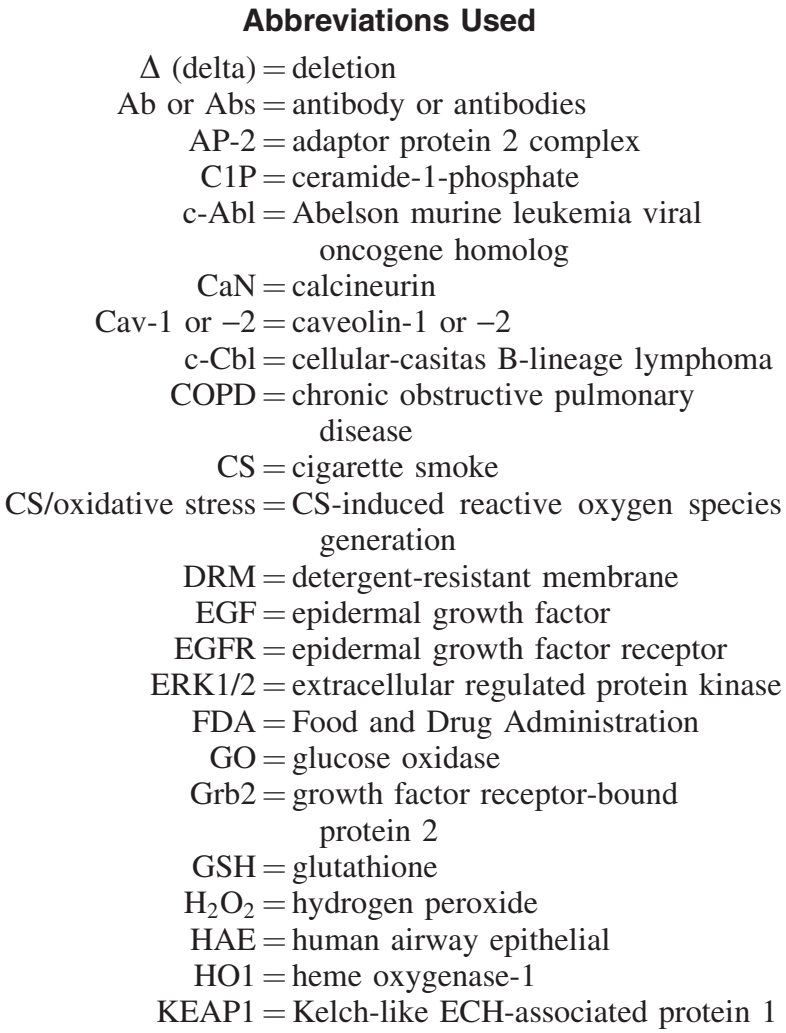 \\
\hline
\end{tabular}




\section{Abbreviations Used (Cont.)}

MAPK $=$ mitogen-activated protein kinase miRNA $=$ microRNA

MMPs $=$ matrix metalloproteases

$\mathrm{MT}=$ mutant

$\mathrm{NAC}=\mathrm{N}$-acetyl cysteine

$\mathrm{Nrf} 2=$ nuclear factor (erythroid-derived 2)like 2

$\mathrm{NSCLC}=$ non-small cell lung cancer

nSMase $2=$ neutral sphingomyelinase 2

p38 MAPK $=$ p38 mitogen-activated protein kinase
$\mathrm{PTP}=$ protein tyrosine phosphatase

ROS $=$ reactive oxygen species

$\mathrm{RTK}=$ receptor tyrosine kinase

$\mathrm{SER}=$ serine

$\mathrm{SFK}=$ Src family kinase

$\mathrm{SM}=$ sphingomyelin

SMase $=$ sphingomyelinase

$\mathrm{Src}=\mathrm{v}$-src sarcoma homolog

TKIs $=$ tyrosine kinase inhibitor(s)

$\mathrm{TNF}-\alpha=$ tumor necrosis factor $-\alpha$

$\mathrm{WT}=$ wild type

$\mathrm{Y}$ or $\mathrm{Tyr}=$ tyrosine 